\title{
LA EQUIDAD SEGÚN FERRAJOLI Y LA EQUIDAD SEGÚN ARISTÓTELES: UNA COMPARACIÓN CRÍTICA*
}

\author{
Jesús Vega \\ Universidad de Oviedo
}

RESUMEN. En este trabajo se hace un análisis crítico de la idea de equidad de FERRAJOLI. Para discutir la concepción cognoscitivista de la jurisdicción defendida por el teórico italiano y el lugar que la equidad ocupa en ella (como «poder de connotación», junto a los poderes de «denotación», "comprobación fáctica» ( «disposición») se propone una comparación crítica con la teoría clásica de la equidad de ARISTÓTELES. Esta comparación contrasta ese modelo positivista con el modelo pragmático de las reglas y de la deliberación judicial como razonamiento práctico que se deriva de la idea aristotélica de "prudencia» y se encuentra en el trasfondo de la tesis de la epieikeia como "corrección de la ley». A partir de aquí se muestran, por un lado, las insuficiencias del planteamiento ferrajoliano de la jurisdicción basado en una idea de «verdad» deudora de la dicotomía positivista hecho-valor, argumentando que su tesis de la equidad como "connotación de lo que la ley denota" y "comprensión de las circunstancias de hecho del caso" mantiene en el fondo la misma posición del formalismo clásico ilustrado. Por otro lado, se destacan las inconsistencias que tal comprensión supone para el proyecto de constitucionalismo positivista de FERRAJOLI, subrayando que la función judicial, y particularmente en el Estado constitucional, es indisociable de la idea de verdad como corrección práctica y de la coherencia como ideal metódico.

Palabras clave: FerRajol, Aristóteles, equidad, práctica, praxis, epieikeia, connotación, denotación, jurisdicción, dicotomía hecho-valor, corrección, razonamiento judicial, valores, legislación, coherencia, principios y reglas, positivismo jurídico, concepción argumentativa del derecho.

\section{Ferrajoli's Equity and Aristotle's Equity: A Critical Comparison}

ABSTRACT. The purpose of this paper is to elaborate a critical approach to FERRAJol's conception of equity. Its author undertakes a critical analysis on the cognitivist conception of jurisdiction to be found in the Italian author, particularly on the role played by equity thereof (as «power of connotation» coming along with the "denotation power», "fact finding power» and "ethical-political disposition power» of the judge) using for this purposes ARISTOTLE's classical theory on equity. In this comparison, FERRAJOLI's positivist model is confronted with ARISTOTLE's pragmatic model of rules and with judicial deliberation as practical reasoning, this latter derived from his notion of «prudence» underlying the concept of epieikeia as «correction of the law». It is then that the deficiencies of FerRAJoli's approach to jurisdiction, based on a conception of the notion of truth following the positivist fact-value dichotomy, are observed. The author argues that FERRAJOLI's thesis on equity as "connotation of what is denoted by the law» and "understanding of the factual circumstances of the case» really tantamount to the classical formalist conception on jurisdiction. Moreover it is argued that holding this understanding of jurisdiction turns FERRAJOLI's positivist constitutionalism inconsistent. For the judicial function, especially in the constitutional rule-of-law state, needs to be considered as inseparable from the notion of truth as practical correction and from the methodical ideal of coherence.

Keywords: Ferrajol, Aristotle, equity, practice, praxis, epieikeia, connotation, denotation, jurisdiction, fact-value dichotomy, correctness, legal reasoning, values, legislation, coherence, rules and principles, legal positivism, argumentative conception of law.

* Fecha de recepción: 4 de noviembre de 2013. Fecha de aceptación: 25 de noviembre de 2013.

Este trabajo ha sido realizado en el marco del proyecto de investigación Constitucionalismo y argumentación (DER2010-20132) financiado por el Ministerio de Ciencia e Innovación. 
1.

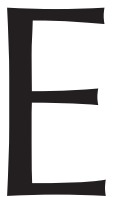

n Derecho y razón L. FerRAJOLI atribuye a la idea de equidad un papel que juzga decisivo en su concepción de la jurisdicción y que se manifestaría en lo que llama el «poder de connotación» del juez, entendido como «poder equitativo», «comprensión equitativa» o «discrecionalidad equitativa». La idea se mantiene en su obra posterior (incluyendo su gran Principia iuris) con denominaciones similares: ahora reformulada como «ponderación equitativa de las circunstancias de hecho», con intención distanciadora frente a la «ponderación de principios» de ALEXY ${ }^{1}$. El propósito de este trabajo es hacer un análisis crítico de esa concepción de la equidad en la medida en que se presenta como una superación tanto de la concepción tradicional de la equidad de raigambre iusnaturalista, que la liga a una normatividad superior al derecho positivo, como de la concepción moderna del legalismo ilustrado, el primer positivismo jurídico, que destierra por completo la equidad de la función jurisdiccional. Para desarrollar esta crítica adoptaré como marco de referencia la teoría de la equidad de ARISTÓTELES, a la que considero una teoría también irreductible a ambas tradiciones —iusnaturalista y iuspositivista - y que contiene no sólo una visión de la jurisdicción muy diferente a la defendida por FERRAJOLI sino también una concepción general del derecho en mi opinión filosóficamente mucho más adecuada.

Mi exposición se va a centrar, pues, en la teoría ferrajoliana de la jurisdicción: en su concepción de la función judicial y del razonamiento de aplicación del derecho por los jueces expuesta en Derecho y razón. Pero tiene, como digo, repercusión sobre el conjunto de la concepción filosófica del derecho subyacente. No ya porque la teoría de la jurisdicción (junto con la teoría de la legislación) constituya desde luego un ingrediente central de cualquier teoría del derecho, sino sobre todo porque la noción de «equidad» de cuyo uso por FERRAJOLI voy a ocuparme aquí puede mostrarse como una especie de concepto «parteaguas», un auténtico experimentum crucis, para discriminar y clasificar entre concepciones del derecho (tanto actuales como históricas). De cómo esa noción sea entendida depende mucho más que una determinada forma de aproximarse al razonamiento judicial: clasifica toda la teoría del derecho de referencia, por ejemplo, como positivista o iusnaturalista, formalista o antiformalista, logicista o pragmatista... y también, en nuestros días, como positivista o post-positivista. Ello se pone de manifiesto con claridad en los términos de la actual discusión sobre el «constitucionalismo» como nuevo paradigma de la filosofía jurídica: particularmente, en el debate que el propio FERRAJOLI (2012) plantea entre el constitucionalismo que llama «garantista» (el suyo), que entiende como «positivista» (la culminación y perfeccionamiento en realidad del positivismo jurídico) y el constitucionalismo que llama «principialista»o «argumentativo» al que concibe como anti-positivista o iusnaturalista. Una de las cosas que en este trabajo se intenta mostrar es que también la idea de equidad tiene mucho que decir en este debate.

Los supuestos desde los que va a discurrir mi crítica son sin duda, aceptando la clasificación de FERRAJOLI, los de una concepción «principialista» o argumentativa. Sin

1 Cfr. Ferrajoli, 2011a: I, 836; 2011b: 44 y ss.; 2011-2012: 21; 2012: 810 y ss.; 2013: $\ 4$. 
embargo, eso no significa que tenga que ser una concepción ni antipositivista ni iusnaturalista, como el gran teórico italiano sostiene. No es «antipositivista» si por tal se entiende un rechazo frontal de todas las tesis del positivismo jurídico, cosa que ninguna filosofía del derecho mínimamente seria — no metafísica — podría siquiera intentar. No cabe dejar de lado el acervo conceptual acuñado por esa corriente de la teoría jurídica desarrollada — digamos_ desde la gran teoría kelseniana en adelante en su análisis del derecho como institución o sistema social apoyado en normas positivas, realmente existentes. Cuestión distinta es aceptar como suficiente el método positivista de abordar ese objeto positivo. Porque el principal déficit del iuspositivismo es precisamente de cariz metodológico o epistemológico: estriba en cómo construye o estima fundado el «hecho del derecho positivo». De ahí surge una concepción filosófica del derecho claramente insuficiente. En efecto, en la tesis de la positividad de la institución del derecho van incluidas (entre otras, como la del descriptivismo) dos subtesis mucho más discutibles: primero, su reducción exclusiva a norma (o sistema de normas: un sistema vinculado a la autoridad coactiva estatal), y segundo, su autorreferencia justificativa, que supone la insularidad de esa institución respecto de las demás categorías normativas conexas (fundamentalmente, las morales y políticas). La primera tesis (el normativismo) dejaba abierto el hiato entre normas y decisiones prácticas (hiato cerrado de formas diversas, desde el formalismo logicista al simple decisionismo voluntarista pasando por la tesis de la discrecionalidad). Según la segunda tesis, el derecho «como es» resulta ser una norma (un «deber ser») que, sin embargo, se comportaría al parecer como un «hecho» no sólo respecto de la realidad social sino también respecto de los demás dominios normativos con los cuales mantiene sin embargo innegables relaciones genéticas y de continuidad material o justificativa. Con ello el positivismo jurídico se autocondena a una desconcertante paradoja epistemológica: tener que desarrollar una metodología basada en la dicotomía hecho-valor —una dicotomía superada ampliamente ya en las demás ciencias sociales_- para probablemente el único ámbito —el derecho- en el cual no puede ser mantenida coherentemente. Y no puede serlo sencillamente porque es una metodología impotente para dar cuenta en términos científico-objetivos (tal como pretende) de la práctica real de los sistemas jurídicos positivos, que es eminentemente una práctica de producción de valores, indisociable por tanto de alguna concepción de la justicia. La paradoja, entonces, es que en el mejor de los casos una concepción positivista cumplirá funciones ideológicas (o de justificación endoprofesional) respecto de la realidad positiva jurídica. Y si la despolitización y la neutralización moral de la normatividad del derecho pudieron ser ideológicamente funcionales también en sentido positivo en relación con el proceso de formación del Estado de derecho moderno, no parece que pueda decirse lo mismo en relación con los Estados constitucionales de derecho contemporáneos. Una vez que éstos se caracterizan por la explícita incorporación en una constitución normativa de valores ético-políticos como los expresados en los derechos fundamentales para su irradiación a lo largo de todo su despliegue práctico, carece de sentido ya la operación ideológica de «blindaje» justificativo de las normas jurídicas en términos de autoridad. El énfasis se desplaza desde éstas al derecho como un sistema de prácticas institucionalizadas que se sirve de las normas para promover determinados fines y valores de carácter político-moral en las relaciones sociales: por tanto, también hacia el carácter esencialmente argumentativo y justificativo de esas prácticas (ATIENZA, 2005: 72 y ss.), que han de consistir en 
tender puentes con la moralidad y con la política a la hora de resolver los conflictos y desacuerdos más prominentes que se plantean en una determinada sociedad. El modo como las instituciones jurídicas positivas se organizan en el Estado constitucional de derecho impone, por tanto, una metodología post-positivista, o — aceptando la terminología dominante- «constitucionalista». El propio constitucionalismo de FERRAJOLI reconoce ampliamente este hecho y, sin embargo, se concibe a sí mismo no sólo como «superación» sino también como «reforzamiento» de la corriente central del iuspositivismo, en vez de considerarlo un ciclo agotado. Así, la epistemología de FERRAJOLI sigue siendo esencialmente la misma epistemología positivista y conserva por lo tanto las dos tesis anteriores. Por un lado, mantiene la operación de blindaje estructural de la normatividad jurídica, sólo que ahora reiterada y reaplicada al nivel constitucional (los valores han dejado de ser el deber ser del derecho para convertirse en el deber ser en el derecho). Por otro lado, las normas (incluyendo los principios) siguen siendo «hechos» autoritativos, es decir, reglas asumidas como axiomas preestablecidos que se comunican con las decisiones jurídicas ex opere operato, mediante procedimientos esencialmente lógico-semánticos, subsuntivos o clasificatorios, y no en términos de algún tipo de argumentación práctica que haga intervenir principios y valores (como la ponderación). Consecuentemente, queda suprimida toda conexión de naturaleza justificativa entre derecho y moralidad crítica, sea ética o política ${ }^{2}$.

Las insuficiencias de la epistemología positivista se conservan en las tesis de FERRAJOLI sobre la jurisdicción. La asunción de la dicotomía hecho-valor es visible en dos postulados básicos mutuamente inseparables y realimentados. En primer lugar, el postulado de la exclusión o eliminación de los juicios de valor del núcleo de la jurisdicción, que lleva a centrar la racionalidad de ésta en los juicios fácticos: el proceso judicial es fundamentalmente cognoscitivo, presidido por la idea de verdad y campo de acción de la lógica en términos de esquemas lingüístico-semánticos centralmente subsuntivos. En segundo lugar, la consideración de los valores, de los juicios de valor ${ }^{3}$, como un ámbito esencialmente irracional o a-racional, ajeno a la verdad y la logicidad, perteneciente a la esfera de lo puramente subjetivo, preferencial o discrecional. El primer postulado da por sentado que si la jurisdicción es racional, lo será en la medida en que responda a una racionalidad tendencialmente teorética (en el límite, científica). El segundo postulado asume que si los valores quedan fuera de la racionalidad es precisamente por ser de naturaleza «práctica»: lo práctico para la epistemología positivista queda fuera del conocimiento, de lo teórico; los juicios de valor no son sino «válvulas de escape» de las subjetivas tomas de posición morales y políticas del juez (por ejemplo, de sus ideologías, concepciones de la vida, etc.).

Lo que defenderé es que estas premisas epistemológicas positivistas en torno a la jurisdicción que derivan de la mencionada dicotomía hecho-valor — cuya presencia es fácil rastrear en tesis del iuspositivismo del siglo Xx como la Reinheit kelseniana, la distinción hartiana entre puntos de vista interno y externo o las tesis de las fuentes sociales

2 Es la manera «dualista» de enfocar las relaciones del derecho con la ética y la moralidad política a la que se refiere DwORKIN (2011: 402 y ss.). Cfr. FERRAJOli (2000: 868 y ss.) (en adelante todos los números entre paréntesis sin mención de autor serán referencias a esta obra).

3 Asumo en lo que sigue la definición de «juicios de valor» (Werturteile) o «valoraciones» (Wertungen) propuesta clásicamente por M. WEBER [1917 (1973): 489]: «Todas aquellas "apreciaciones prácticas" de un fenómeno en el cual pueden influir nuestras acciones al aprobarlo o reprobarlo». 
y la discrecionalidad - componen una visión de la función judicial que, en esencia, sigue siendo la misma que la del viejo positivismo legalista, habitualmente considerada «formalista» (y clásicamente representada en formulaciones ilustradas muy conocidas de BECCARIA o MONTESQUIEU que no hace falta repetir aquí: las relativas al «silogismo perfecto» y al poder judicial «nulo» porque es «boca de la ley»). Constituye, por lo tanto, como tantas veces se ha dicho, cuando menos una concepción enormemente simplificadora, epistemológicamente errónea e ideológicamente deformadora de lo que usando una expresión del propio FERRAJOLI podemos llamar la «fenomenología del juicio». Sin embargo el jurista italiano da por evidente que su modelo de jurisdicción se distancia decisivamente, superándolo, del formalismo legalista y de su «tosca» y «obtusa» epistemología $(158,165,201)$. Es aquí donde entra en juego el concepto de «equidad». FERRAJOLI estima que este aludiría precisamente a un aspecto fundamental de la aplicación del derecho erróneamente ignorado por ese primer positivismo y que su propia teoría, en cambio, recupera como elemento intrínseco e insuprimible de la jurisdicción. Sin embargo, lo cierto es que la concepción ferrajoliana de la equidad no supone avanzar un paso sobre la metodología del formalismo legalista clásico: mantiene intacto su método y no añade realmente nada novedoso (como pretende) a la forma de entender la racionalidad de la jurisdicción. Ésta sigue teniendo que ver solamente con la verdad, como racionalidad fundamentalmente semántica, relativa a la denotación de la ley, mientras que la equidad es ajena a la verdad, es un asunto meramente pragmático, relativo a la connotación o valoración del juez. La dicotomía hecho-valor se alza como el obstáculo insuperable que impide que la equidad pase a formar verdaderamente parte de las reglas de racionalidad de la jurisdicción. Con ello el intento de superación del «paleopositivismo» emprendido por FERRAJOLI está condenado a resultar fallido.

Tal superación sí es, sin embargo, posible si retomamos con rigor el concepto aristotélico (adviértase: no «iusnaturalista») de equidad. Este concepto cuenta con una tradición milenaria tras de sí, documentable en todas las tradiciones jurídicas (pensemos en la aequitas romano-canónica, o en la equity anglosajona). Desde un punto de vista filosófico-jurídico, está en efecto históricamente asociado a la tradición iusnaturalista, pues la equidad (al menos desde TOMÁs DE AQUiNo) fue enlazada a lo «justo natural» ${ }^{4}$ y posteriormente (en el iusnaturalismo deontológico y en el neotomismo) a la moral. De ahí el rechazo visceral que generó por parte del primer positivismo, cuando pudo verse en la equidad (al igual que en la actividad misma de interpretación por parte del juez) un compromiso de la soberanía del legislador y una suerte de vía abierta al «funesto arbitrio de los jueces» (por usar la expresión clásica de FILANGIERI) o (según la equivalente y no menos clásica en el ámbito anglosajón de SELDEN) el peligro de «convertir los zapatos del juez en la unidad de medida de la ley». Similares razones lo desterraron de la corriente central del positivismo del siglo XX, ya que —además de su rancia herencia iusnaturalista, que lo hacía incompatible con la tesis de la separación - la equidad venía a poner en cuestión la tesis de la discrecionalidad judicial (estrechamente vinculada al «modelo de las reglas»), lo que para el positivismo hartiano o raziano la situaba más allá de los límites del derecho (SHINER, 1994: 1248 y ss.). Ahora bien, lo que importa destacar es que la noción de equidad es en realidad

\footnotetext{
4 Tomas de Aquino, In dec. Eth., V, 16, 774.
} 
anterior a la dicotomía iusnaturalismo-positivismo y conceptualmente independiente de sus avatares históricos. Se remonta a la vieja idea aristotélica de la epieikeia como «corrección de la ley» de ARISTÓTELES expuesta en la Ética a Nicómaco y en la Retórica. Y cabe defender que esta teoría contiene ya una superación de la controversia iusnaturalismo-positivismo (VEGA, 2010).

FERRAJOLI hace una interesante y documentada reconstrucción del periplo histórico de la noción — «atormentada pero fundamental» (156) — de equidad. Es muy sugestiva la manera en que presenta esa historia como repleta de equívocos y malentendidos, como corresponde al tópico en que se convirtió, especialmente al ser ideológicamente interpretada desde dicotomías tales como formalismo-antiformalismo y iuspositivismo-iusnaturalismo. Sin embargo, en esa reconstrucción FERRAJOLI comete en mi opinión dos graves errores de fondo. En primer lugar, atribuye equivocadamente el origen de esos equívocos a la propia teoría de la equidad de ARISTÓTELES. En segundo lugar, su aproximación al concepto (y a su historia) sigue presa de la disyuntiva que él mismo critica entre interpretaciones iuspositivistas y iusnaturalistas. Ambos errores provienen sencillamente del hecho de que su concepción de la equidad es ella misma positivista y, en el fondo, sigue siendo idéntica a la del legalismo clásico ilustrado, lo cual le lleva a desfigurar la doctrina aristotélica y a articular una teoría de la equidad que al cabo no desempeña papel sustantivo alguno en la racionalidad de la aplicación judicial del derecho. Es esto lo que termina lastrando con insuperables inconsistencias teóricas — como intentaré mostrar - su proyecto garantista y constitucionalista.

Así, después de analizar el texto aristotélico y reconocer que «sigue siendo todavía hoy la explicación más clara y penetrante que nunca se haya ofrecido de la noción de equidad» (156), FERRAJOLI concluye que la concepción de ARISTÓTELES es sin embargo «insatisfactoria» y «errónea» por cuanto se basa en la idea de que el carácter general y abstracto de la ley entraña su condición incompleta, omisiva o constitutiva de un error (del legislador), y con ello en la idea de que la equidad es una «corrección» extra, ultra o contra legem a cargo del juez. De aquí arrancaría, a su juicio, el equívoco arrastrado (nada menos que) a lo largo de toda la historia del pensamiento jurídico, según el cual la equidad se contrapone a la legalidad, dado que comportaría ir «más allá de la ley escrita» para concebirse como un «modelo de juicio complementario, supletorio o alternativo», como «fuente de derecho alternativa a la legalidad, o bien como instrumento más o menos excepcional de interpretación y de integración de la ley»: «con la consecuencia de que mientras su aceptación sirve para favorecer orientaciones sustancialistas y decisionistas contrarias al principio de legalidad [...], su rechazo resulta engranado con orientaciones obtusamente formalistas y abstractamente legalistas» (157-158). Frente a tal concepción heredada, que FERRAJOLI considera fruto de una teoría inadecuada de la jurisdicción — «y más a menudo de la ausencia de cualquier teoría» (158)—, elabora su propia propuesta: una «noción semántica de la equidad» basada en la distinción entre legalidad como denotación y equidad como connotación (entre lengua legislativa y lenguaje judicial).

Pues bien, lo que voy a intentar mostrar en las páginas que siguen es cómo FERRAJOLI malinterpreta a ARISTÓTELES al atribuirle semejante contraposición entre legalidad y equidad, y que su planteamiento no capta el verdadero significado epistemológico de la equidad como corrección (donde se encuentra el verdadero núcleo de la idea 
aristotélica) y su importancia para una cabal concepción filosófica del derecho. Debido a ello, su propia propuesta de la equidad como connotación no ofrece en realidad ningún enfoque novedoso sino que es una manera sofisticada y artificiosa de mantener la misma concepción subsuntiva clásica del silogismo judicial propia del positivismo legalista ilustrado (cuyo «obtuso» rechazo de la equidad pretende sin embargo haber superado). Es esta concepción positivista en realidad la que se caracteriza por enfrentar entre sí legalidad y equidad como dimensiones contrapuestas y mutuamente excluyentes del juicio, algo que la teoría de la epieikeia de ARISTÓTELES no sólo no sostuvo nunca sino que expresamente rechazó en su reconstrucción del funcionamiento de la «justicia legal» (nomikon dikaion) que rige la racionalidad de la función judicial, en la que se hace presente la equidad como «corrección de la ley» representativa de una forma «superior» de justicia. En esa medida, la concepción positivista habría sido ya reconocida y criticada por ARISTÓTELES (naturalmente, como opción teórica y metodológica, no como doctrina histórica, pues sólo figuradamente puede decirse que sea un «post-positivista: $c f r$. ATIENZA, 2013: 96 y ss.; VEGA, 2013a). Que las insuficiencias del positivismo jurídico quedan perfectamente diagnosticadas y superadas desde el marco conceptual aristotélico se comprueba cuando contrastamos la teoría de la equidad de FERRAJOLI con la teoría de la equidad de ARISTÓTELES y las respectivas concepciones del derecho que representan.

La comparación crítica entre ambas visiones de la equidad permite mostrar también —y este es el segundo punto que antes subrayaba — que la teoría de la epieikeia no es tampoco iusnaturalista (ni menos aún «premoderna»). La concepción aristotélica revela más bien una comprensión pragmática y constructivista de las reglas jurídicas directamente conectada con su concepción política del imperio de la ley y su concepción moral de la prudencia, ambas confluyentes por un lado en la teoría del nomos y del «gobierno de las leyes» y, por otro, en la «justicia legal» como orthos logos o justificabilidad racional de la ley. A esta concepción subyace toda una compleja teoría filosófica de la práctica, de lo que ARISTÓTELES llama praxis (moral, política y jurídica), que resulta solidaria de una «razón práctica» (reflejada en el concepto de phronēsis, «prudencia») que actúa no sólo en función de reglas sino también de valores (y sobre cuya relevancia filosófica para la iurisprudentia es, creo, innecesario insistir). Bajo este modelo de racionalidad práctica queda desbordada la contraposición dicotómica hechovalor tal como ésta se proyecta sobre la metodología judicial: las normas jurídicas no se comprenden ya como «hechos» que deban marginar los juicios de valor del juez (por ejemplo como «límites»o «controles» o «garantías» frente a sus tomas de posición) sino como piezas de un razonamiento práctico que debe estar justificado en términos de corrección o validez sustantiva y, por tanto, en términos de valores. Las propias normas jurídicas son proposiciones prácticas per eminentiam cuyo fundamento no deja de responder a principios y valores ni siquiera cuando se analizan como hechos «autoritativos». Y precisamente en esa referencia a los valores operativos en la práctica de aplicación judicial, en la prudencia judicial (dikastikēe —valores de justicia, materiales, y no solamente valores lógicos o formales ligados a la generalidad de las reglas - se encuentra una clave fundamental de la tesis de la unidad de la razón práctica — que no es otra que la unidad del valor, como apunta DwORKIN (2011: 1 y ss., 255 y ss., 402 y ss.) - , tesis que conduce a conectar interna y necesariamente el derecho con la moral y la política (en términos dialécticos, no armonistas, esto es, presuponiendo el conflicto 
y el desacuerdo entre concepciones valorativas en vista de su resolución más bien que postulando sin más su separación). Esta idea es un hilo rojo del postpositivismo o constitucionalismo contemporáneo (Dworkin, NinO, AlEXY, ATIENZA) que no cabe ya calificar como iusnaturalista (excepto justamente desde las premisas positivistas). ARISTÓTELES no es obviamente un «constitucionalista», como decía, pero sí un defensor de una concepción racionalista del Estado de derecho mucho más próxima a lo que nuestros Estados constitucionales están demandando hoy de lo que a menudo tiende a suponerse. En su filosofía jurídica, y particularmente en sus tesis sobre la epieikeia, antes que una arcaica doctrina iusnaturalista, cabe encontrar aquella teoría del derecho como práctica que podría permitir al constitucionalismo desarticular algunas de las dicotomías heredadas de la tradición iuspositivista. Veamos si ello es así a propósito de un planteamiento positivista de la jurisdicción como el de FERRAJOLI.

\section{2.}

Resumamos rápidamente, para empezar, las ideas principales de la concepción de la jurisdicción trazada en Derecho y razón. Para FERRAJOLI la jurisdicción es un poder al que caracteriza como «saber-poder». Serían cuatro las dimensiones que conforman el poder judicial: i) el poder de denotación, ii) el poder de comprobación, iii) el poder de connotación y iv) el poder de disposición.

El poder de denotación tiene que ver con la determinación de la ley aplicable, la calificación jurídica de los hechos y la interpretación de la ley, donde rige el principio auctoritas, non veritas facit legem. El poder de comprobación tiene que ver con la dimensión probatoria del juicio: la determinación de los hechos del caso, donde rige el principio veritas, non auctoritas facit iudicium. El poder de connotación va referido a la consideración y apreciación de lo singular de cada caso por el juez. El poder de disposición remite a valoraciones de naturaleza ético-política del juez.

Para FERRAJOLI estos cuatro poderes son magnitudes no independientes sino correlacionadas entre sí en términos de proporción inversa: cuando unos aumentan, otros disminuyen correlativamente. Además, hay una gradación jerárquica entre ellos: el poder de denotación y el de comprobación conforman el núcleo «irreducible» (166) de la jurisdicción, por ser aquellos que le proporcionan su carácter cognoscitivo como «saber», mientras que el poder de connotación deja de ser ya iuris-dictio para pasar a ser iuris-prudentia, en razón de su naturaleza intrínsecamente valorativa y discrecional y, por último, en el extremo del polo, el poder de disposición, deja de ser ya propiamente jurisdicción como «saber» para pasar a ser nudo «poder»: un poder «patológico» que crece a expensas de los demás («fisiológicos»), de manera que si se reducen éstos la vinculación a la legalidad que define a la jurisdicción deja paso al arbitrio decisionista del poder judicial: un poder ético-político descontrolado y no sometido ya al poder legislativo ni, por tanto, al derecho.

Resulta muy claro cuáles son los valores que rigen esta gradación. Los dos primeros poderes (denotación y comprobación) responden al valor de verdad: son poderes de verificación. Se trata de la verdad jurídica (la denotación) y la verdad fáctica (la comprobación). Son por ello los únicos que responden propiamente a logicidad 
(deducción e inducción, respectivamente) y, por tanto, a racionalidad. Tienen una dimensión semántica. Conforman el «saber» en la dualidad «saber-poder». En cambio, los dos últimos son poderes para los que no rige el valor de verdad, sino otros valores: valores morales y políticos. Se trata de los valores desde los cuales el juez aprecia las circunstancias específicas del caso concreto (connotación) y aquellos que presiden genéricamente el ejercicio de su función como poder decisorio estatal (disposición). Por tanto, son intrínsecamente irracionales, ajenos a toda logicidad. Tienen una dimensión puramente pragmática. Conforman el «poder» en la polaridad «saberpoder».

Los «por tanto» subrayados en el párrafo anterior expresan la perfecta incorporación de la dicotomía hecho-valor en la concepción ferrajoliana de la jurisdicción. La cual se ve amplificada ad libitum en una cadena de dicotomías correlativas: cognoscitivismo/no cognoscitivismo, objetivo/subjetivo, conocimiento/acción, teórico/ práctico, saber/poder, semántica/pragmática, determinación/discrecionalidad, subsunción/valoración, reducible/irreducible... Estos dualismos, como veremos, tienen mucho de retórico y sirven fundamentalmente para extremar las cosas en términos de falsas oposiciones. Porque cuando se desciende a los detalles de cada uno de los cuatro poderes se ven obligados a atenuarse notablemente: así, tanto la denotación como la comprobación contienen elementos de decisión o elección valorativa, mientras que la connotación y la disposición, que son esencialmente valorativas (sobre todo la última), resultan sin embargo finalmente por fuerza reconducidos al ámbito de lo «argumentable» racionalmente $(120,173)$. Esto sugiere ya que en la descomposición analítica de la jurisdicción en ese cuadro de poderes está ausente una teoría de la práctica que los muestre unitaria y adecuadamente ordenados: hay una inconsistencia de fondo en presentarla como fundamentalmente cognoscitiva (teórica: un «saber») cuando desde el principio tiene que ser concebida como una actividad eminentemente práctica o valorativa (un «poder»). Una tal teoría es la que, en cambio, sí nos ofrece la concepción aristotélica de la praxis judicial.

Pero donde el dualismo básico hecho-valor, característico del esquema metódico positivista, se hace sobre todo transparente es en la distinción metafórica ferrajoliana entre lo «fisiológico» y lo «patológico». Los tres primeros poderes son fisiológicos porque no deben contener en rigor juicios de valor (sólo la connotación los comprende, pero veremos enseguida que no compiten con la verdad, es decir, con los hechos). Los hechos son el centro del razonamiento judicial: el hecho de la ley (o sea, la norma) y los hechos del caso (o sea, las circunstancias a las que ésta se aplica por el juez). Mientras que los valores (es decir, los valores distintos de la verdad: los valores morales y políticos; llamémoslos «valores prácticos») quedan segregados de ambas clases de hechos. El criterio de esta segregación parece ser la presencia de procedimientos lógicos que introducen la requerida objetividad teórica: la subsunción deductiva bajo las pautas generales de la norma (verdad jurídica) y el razonamiento inductivo por el que se prueban los hechos del caso (verdad fáctica). A la lógica se le supone, pues, la capacidad para neutralizar los juicios de valor, y de su operatividad resulta que el juicio sea fundamentalmente una actividad lógico-cognoscitiva, un razonamiento teórico. La verdad es el valor que opera como género rector del razonamiento judicial, subordinante de los demás. Este es el efecto del primer postulado metodológico positivista al que hacíamos referencia más arriba. 
Y así — segundo postulado- los valores prácticos, fuera de este marco, quedan confinados al espacio de lo irracional. Los juicios de valor son subjetivos y arbitrarios porque no poseen valor de verdad: los términos valorativos carecen de significado veritativo, no son verificables ni refutables, no connotan ni denotan nada objetivo, no sólo son «indeterminados» sino en realidad «indeterminables», pues «no connotan propiedades objetivas sino que sólo expresan las actitudes y valoraciones subjetivas de quien los pronuncia» (120). De manera que representan aquello que debe ser limitado, controlado, reducido: los juicios de valor son la fuente de indeterminación del razonamiento judicial, del cual deben ser expulsados. Su presencia señala el comienzo de la «patología» del razonamiento judicial: precisamente en la medida en que el juez quede «libre» para valorar, pues en ese momento dejará de actuar racionalmente. Por eso el poder de disposición, intrínsecamente ético-político, es siempre y por estructura patológico. Los juicios de valor no representan sino la potencial arbitrariedad, irrestricta discrecionalidad e irracionalidad del juez, un peligro siempre acechante que «infiltra» peligrosamente, casi se diría que «infecta» (siguiendo con la metáfora) la labor jurisdiccional y que debe ser combatido y neutralizado a toda costa. Y esa es la función que cumple la verdad (la denotación y la comprobación), que opera como una suerte de muro de contención — racionalizador- de los juicios de valor irracionales del juez (un «antibiótico» contra el virus en potencial expansión que éstos suponen). La verdad —el poder de verificación del juez, fáctica y jurídica — es «el espacio mínimo irreducible» de la racionalidad judicial ${ }^{5}$. Sin él no hay poder que pueda llamarse jurisdiccional, sino sólo poder o nuda valoración discrecional. Cuando ese reducto mínimo comience a ceder por efecto de las «carencias e imperfecciones» de la decidibilidad en términos de verdad que ofrezca la ley (como las indeterminaciones semánticas o las antinomias, en lo que respecta a la ley, o la ausencia de garantías en lo que respecta a la prueba), simultáneamente aumentará el quantum de irracionalidad de la aplicación del derecho, al abrirse la compuerta a las valoraciones del juez. Hasta el punto de que superado un cierto grado dejaría de ser ya jurisdicción para pasar a constituir simple imposición de las opiniones morales o políticas del juez (en lugar de las del legislador, que es el único a quien en el Estado de derecho se reserva legítimamente un tal poder de disposición o de decisión política, cuyos términos el juez sólo puede constatar y verificar) ${ }^{6}$. Volvemos a toparnos aquí con la inconsistencia básica antes referida: si los juicios de valor del juez son el ejercicio de un poder delegado por el legislador y en tal medida sólo son jurídicamente racionales en cuanto controlados o limitados por sus reglas sustantivas y procesales, entonces de algún modo deben ser asumidos como el centro de la decisión judicial, no su residuo. Dicho de otro modo: aun cuando la lógica (sea deductiva, si hablamos de la universalidad lógica de la ley, sea inductiva, si hablamos de su taxatividad) sea necesaria para canalizar racionalmente los juicios de valor del juez, no sería suficiente para producir la decisión misma. Ésta no puede ser asegurada solamente por procedimientos lógicos: no se explica cómo se pasa de la ley a la decisión sin mediación valorativa. La función «subjetivizante» del valor pasaría a ser entonces un factor

5 «Las sentencias son, en cambio, comprobaciones y exigen por tanto una motivación fundada en argumentos cognoscitivos en los hechos y re-cognoscitivos en el derecho, de cuya verdad, aun aproximativa como lo es toda verdad empírica, depende tanto su validez o legitimación jurídica, interna o formal, como su justicia o legitimación política, externa o sustancial» (FERRAJOLI, 2011a: II, 209).

${ }^{6} \mathrm{Cfr}$. FerRajoli, 2011a: II, 198 y ss. 
positivo y no negativo. Tampoco el objetivo del método podría ser «neutralizar» los juicios de valor, si resulta que la operatividad de la lógica en la decisión no puede ser ella misma desligada de las valoraciones ético-políticas del legislador. Estas objeciones, como veremos, encuentran su solución desde la perspectiva aristotélica.

De cualquier modo, si la intrínseca y correcta fisiología del juicio, tal como FERRAJOLI la presenta, está ligada de ese modo a una actividad centralmente cognoscitiva (o recognoscitiva), aun cuando su ejercicio comporte siempre la intervención inevitable y patológica de juicios de valor más o menos «reducibles», la pregunta previa que cabe plantear es en qué difiere esta teoría de la teoría del «silogismo perfecto» del formalismo ilustrado en donde, fijada la norma y asegurado el hecho, quedaba «mecánicamente» resuelto el juicio ${ }^{7}$. La respuesta de FERRAJOLI es que la diferencia estriba precisamente en la equidad. Veamos si es realmente así.

\section{3.}

Aunque FERRAJOLI, naturalmente, no desconoce los problemas de indeterminación, vaguedad y textura abierta del lenguaje legislativo (puestos de manifiesto por el iuspositivismo contemporáneo) ni la distancia que separa a la determinación judicial de los hechos de una reconstrucción teórico-objetiva como la que es propia de la ciencia, sigue manteniendo la tesis central de que tanto el poder de denotación como el de comprobación constituyen esencialmente inferencias teóricas, verificables o falsables. La actividad judicial es originariamente un «poder» (y de ahí que su ejercicio suponga valoraciones), pero un «poder de cognición» (40), un «saber-poder», es decir, «una combinación de conocimiento (veritas) y de decisión (auctoritas)» en la que «cuanto mayor es el saber tanto menor es el poder (y viceversa)» $(45-46,14)^{8}$. De ahí que su posición en cuanto al poder de denotación y de comprobación sea que ambos están esencialmente orientados a la verdad objetiva (168). Una idea ésta - la de vincularlo a la idea de verdad - que resulta incontestable, por supuesto, desde cualquier posición racionalista en torno al proceso judicial (TARUFFO, 2002: 80 y ss., 327 y ss.). Como apunta FERRAJOLI la aplicación judicial se caracteriza por ser un «razonamiento», no un simple decisionismo (64), y ello marca el paso de la mera a la estricta legalidad y jurisdiccionalidad ( 35 y ss., 539 y ss.). Sin embargo, lo que no está tan claro es que esta orientación a la verdad deba consistir en que el nexo entre ambos principios, legalidad y jurisdiccionalidad estrictas, se base en «excluir las valoraciones en lo más posible», sobre todo después de reconocer que la decisión judicial necesariamente ha de ser un razonamiento práctico.

Pero FERRAJOLI sigue entendiendo esas dos inferencias como «teóricas» (65) en la medida en que están regidas por el valor de la verdad. La solución al problema de cómo están conectadas con la decisión del juez (que es práctica) viene dada en su modelo por el poder de connotación, la tercera inferencia, a la que califica como

\footnotetext{
7 «Donde las leyes son claras y precisas el oficio de juez no consiste más que en asegurar un hecho», C. BECCARIA, De los delitos y de las penas (1774), XIV; cfr. IV (1968: 49, 31-32).

8 «En suma, el poder judicial es un poder-saber: tanto más legítimo cuanto mayor es el saber y tanto más ilegítimo cuanto mayor es el poder» (FERRAJOLI, 2011a: II, 210).
} 
inferencia práctica. Así tras la inferencia probatoria inductiva («Ticio ha cometido el hecho $\mathrm{H}$ », cuyas premisas son el conjunto de las pruebas recabadas) y la inferencia normativa subsuntiva («Ticio ha cometido el delito G», cuyas premisas son la conclusión anterior y la definición legal del delito en cuestión y cuya conclusión es la clasificación del hecho probado dentro del concepto jurídico clasificatorio en cuestión), viene - y por este orden - la inferencia propiamente práctica o decisoria (la disposición o fallo): «Ticio debe ser castigado con la pena P». Pues bien, afirma FERRAJOLI: «De estos tres silogismos sólo el tercero incluye normas y por eso es calificable - se piense lo que se piense sobre su naturaleza lógica o para-lógica- como «práctico» o «deóntico» (64). Sólo en este momento —en la derivación del fallo— aparecerían «premisas y conclusiones normativas», pues hasta ahora todo lo que teníamos eran inferencias lógicas (a partir de enunciados descriptivos: de hechos y de normas), es decir, teóricas. De nuevo esta limpia disección analítica resulta controvertible, pues obviamente ya la subsunción y la inferencia probatoria envuelven premisas normativas y conclusiones normativas (en la interpretación, en la imputación), y de ello derivan en buena medida los problemas epistemológicos que exhibe la «verdad jurídica formal» (cuyas condiciones de construcción objetiva no son homologables a las del saber científico incluso cuando se dispone de pruebas de base científica). Es insatisfactorio plantear las relaciones entre la epistemología procesal y la científica exclusivamente en términos del valor de verdad (por ejemplo, oponiendo incertidumbre y plausibilidad a objetividad: 141 y ss.). De nuevo, aunque éste sea un ideal regulativo irrenunciable, necesario, no es sin embargo suficiente para dar cuenta de la inferencia judicial. Sobre ello volveremos después a propósito de las relaciones entre saber teórico (epistēmē) y saber práctico (praxis) en ARISTÓTELES.

Lo que nos importa subrayar ahora es que, en el modelo de FERRAJOLI, este es el momento en que el razonamiento del juez comienza a ser reconocido como un razonamiento efectivamente «normativo» o «práctico» en sentido estricto. Es decir, ahora comenzamos a comprender qué significa que la jurisdicción se considere desde el inicio como un «poder». En realidad está aflorando el poder de disposición del juez, al que FERRAJOLI llama «ético-político» y que, si en su modelo se ve relegado al trasfondo, en realidad como podremos ver está operando desde el principio en primer plano. Se desvela en efecto ahora que el juez no sólo hace afirmaciones verdaderas acerca de la existencia de ciertos hechos y de ciertas normas relativas a ellos sino que también valora. En otros términos: su interpretación se vuelve «operativa» (a diferencia de la «doctrinal», que sería teórica) (53 y ss., 83, 160; cfr. FERRAJOLI, 2011a: I, 221, 533). La jurisdicción aparece como un «saber» al servicio de un «poder». La importancia de la equidad tiene que ver, pues, con la introducción en el juicio del aspecto valorativo, decisorio o justificativo. Y es esta dimensión la que según FERRAJOLI el positivismo formalista ilustrado habría oscurecido con el esquema del «silogismo perfecto», que habría sido pensado en términos indistinguibles de un «silogismo teórico». El error del formalismo positivista es pretender la negación de la dimensión valorativa del juicio (reduciendo el juicio a un mero «saber»), así como el error del decisionismo sustancialista es sobredimensionarla (reduciendo el juicio a mero poder de disposición, a pura decisión ético-política: el poder desnudo, diríamos). El tertium quid que FERRAJOLI nos ofrece para escapar de esta que en su opinión es una falsa disyuntiva es precisamente la equidad como poder de connotación. 
FERRAJOLI retoma aquí la idea básica de la que arranca el tópico de la equidad en ARISTÓTELES según la cual muchas propiedades del caso juzgado no hallan encaje en el marco abstracto y genérico de la norma (156). De ellas no puede predicarse en consecuencia la verdad jurídica. La ley no puede prever todas las connotaciones posibles de los hechos por ella denotados. Estas tienen que ser individualizadas y comprendidas en su concreción particular en cada caso, y eso es la equidad: el poder de connotación del juez.

En opinión de FERRAJOLI esta manera de entender la equidad permite superar todos los «desorientadores malentendidos políticos y estériles contraposiciones teóricas entre equidad y legalidad» (157) que han ido asociados históricamente a este concepto. Malentendidos de los que en última instancia, como se adelantó, viene a responsabilizar a la propia idea aristotélica según la cual la equidad envuelve una «corrección» por el juez de los yerros u omisiones de la ley o del legislador ${ }^{9}$, idea que habría sido acríticamente asumida por la tradición, pues «la reflexión sobre ella no ha progresado mucho de ARISTÓTELES en adelante» (198). De este modo, desde el lado formalista la equidad habría sido entendida como una especie de «derecho supralegal», como un juicio supletorio o alternativo a la legalidad (y por ello proscrito), como discrecionalidad del juez, etc., mientras que por el lado sustancialista se habría visto en ella una remisión al «derecho natural», a la «ética», al «derecho justo», a la «justicia del caso concreto», etc. (197-198). FERRAJOLI no llega a hacerlo, pero podríamos formular esta oposición mediante los lemas dura lex, sed lex (formalismo, textualismo) y summum ius, summa iniuria (antiformalismo, intencionalismo). El equívoco planteado por estas oposiciones queda perfectamente dilucidado, en cambio, dice FERRAJOLI, en cuanto adoptamos una «noción semántica de la equidad». Esta queda sintetizada en la conocida fórmula: «La ley connota lo que el juez denota, y denota lo que el juez connota; e, inversamente, el juez denota lo que la ley connota, y connota lo que la ley denota» (157).

De acuerdo con esa fórmula, la ley determina las propiedades o «características esenciales» que forman la connotación o intensión de las normas y que «determinan la extensión de la clase de los casos individuales denotados por el juez como aquellos de los que la figura legal es predicable en aserciones judiciales aceptadas como verdaderas» (158); mientras que el juez «connota las características accidentales y las circunstancias específicas, no connotables ni denotables legalmente, que forman la intensión de los casos individuales denotados por la ley como miembros de la clase cuya extensión está determinada por la figura de delito por ella connotada» (158, subrayado en el original). Fijémonos en que esta quiasmática fórmula revela de entrada cierta contradicción. Se dice que las circunstancias de cada caso no son «connotables ni denotables legalmente», esto es —en las palabras de ARISTÓTELES - que «no quedan cubiertas por la norma universal»: el problema puesto al descubierto por la equidad es, pues, que las situaciones de la práctica desbordan toda norma preexistente mediante la cual pretenden ser gobernadas, desafiando así a la práctica de aplicación (se superpone en

9 Recordemos el texto aristotélico: «Así pues, cuando la ley se pronuncia en términos universales y surge un caso particular que no queda cubierto por la regla universal, debe corregirse el defecto en que incurre el legislador, es decir, el error que resulta del carácter absoluto de la ley. Esta corrección tiene lugar recurriendo a lo que el legislador mismo hubiera establecido en la ley si estuviera presente y hubiera conocido el caso» (Ética Nicomáquea, V, 10, 1137b, 20-24). 
buena medida, pues, con el problema wittgensteiniano del rule-following) a llevar a cabo una labor interpretativa de índole constructiva (y en los «casos difíciles», a poner en cuestión la norma misma). Y sin embargo, siendo por definición las circunstancias del caso no «denotables», FerRajoli define la equidad como connotación de lo que el legislador denota. Lo que subyace a esta contradicción es de nuevo la pretensión de situar a la inferencia lógico-veritativa en el centro del razonamiento judicial para así erigirla en instancia de neutralización de cualquier valoración de índole extralógica, esto es, práctica. En otras palabras, el intento de reducir lo más posible la connotación a la denotación, de subordinar — en suma - la equidad a la legalidad en la construcción epistemológica del juicio. Lo cual, en realidad, no es sino plantear una solución legalista al problema o, lo que es lo mismo, dejarlo en el fondo irresuelto.

En efecto, legalidad y equidad, dice FERRAJOLI, son «dos aspectos distintos del conocimiento judicial»: el juicio de legalidad es la verificación por el juez «de las características esenciales y comunes que permiten afirmar que un determinado caso individual entra en una determinada clase de delitos connotada por la ley», mientras que el juicio de equidad es «la comprensión de las características accidentales y particulares del caso individual verificado y no connotadas por la ley» (158-159). Subrayo en esta última frase las palabras «accidentales» y «verificado» ${ }^{10}$ porque en ellas radica de algún modo la clave del enfoque ferrajoliano sobre la equidad. Advirtamos cómo esta operación de «comprensión» es residual, parasitaria y, por así decir, inane respecto de la operación de subsunción. Pues, primero, presupone que ya se ha producido esa subsunción (sobre lo cual volveré enseguida) y, segundo, que se ha producido de manera avalorativa (pues es una inferencia puramente lógica). De modo que si nos preguntamos cómo afecta la connotación del juez a su denotación, la respuesta es bien clara: de ninguna manera. La equidad no pone ni quita nada a la denotación, es una suerte de «negativo fotográfico» valorativo de la previa operación lógico-subsuntiva en que dicha denotación se hace consistir y perfectamente inocuo con respecto a ella. Inocuo porque la «comprensión valorativa» de las circunstancias del caso concreto sólo tendría verdadera relevancia para el razonamiento judicial si los juicios de valor que comporta tuviesen algo que decir - como veremos sucede en ARISTÓTELES— respecto de la corrección o adecuación de la norma al caso y afectasen así a las propias condiciones de subsunción e interpretación de la misma. Es decir, cuando se reconociera que el razonamiento judicial tiene un carácter interpretativo en el sentido de DWORKIN —interpretativo de proposiciones prácticas y de prácticas sociales con arreglo a fines o valores- que predetermina las operaciones lógico-subsuntivas involucradas en la aplicación de dichas proposiciones y con ello sus condiciones de verdad, al mostrarlas como una actividad constructiva (DWORKIN, 1986: 47 y ss.; LIFANTE VIDAL, 2013). Dicho de otro modo, cuando la verdad se entienda precisamente como corrección (DWORKIN, 2011: 23-96). Pero no es esto lo que sucede con la connotación de FERRAJOLI, que juega un papel enteramente accesorio desde el momento en que las eventuales valoraciones ético-políticas o de moralidad que pueda involucrar son precisamente «accidentales» en la elaboración del juicio. La equidad se subordina enteramente a la subsunción, la connotación a la denotación (es decir, a la cognición veritativa), que es la operación «esencial» y que, al entenderse en términos de un «lenguaje observacional» al modo neopositivista, expurgado de juicios

${ }^{10}$ En el original sólo aparece subrayado el término «comprensión». 
de valor ${ }^{11}$, queda perfectamente inmunizada como operación puramente lógica. Y así puede concluir nuestro autor: «La equidad no puede ser invocada para sobrepasar a la ley, sino sólo para aplicarla» (164). El argumento ferrajoliano de la equidad, pese a que en apariencia incorpora el momento valorativo del razonamiento judicial, nos devuelve en realidad (circularmente, describiendo una suerte de petición de principio) a la misma teoría legalista del «silogismo perfecto», en la que el razonamiento judicial queda reducido a simple justificación interna o subsunción.

Ese círculo queda paradójicamente evidenciado en las palabras de censura que FERRAJOLI dirige al legalismo positivista, cuestionando su «tenaz» pretensión de reducir el juicio a un silogismo y su consiguiente desconfianza hacia la equidad: «pues la equidad no tiene nada que ver con el silogismo judicial, al no afectar $-\mathrm{y}$ por tanto al no comprometer - al procedimiento de búsqueda y de formación de la verdad procesal, que como se ha visto se refiere a la denotación y no a la connotación judicial» (163). En realidad la teoría ferrajoliana de la equidad reedita, de manera más sofisticada (pero no menos «mecanicista»), el mismo y simplificador esquema de la teoría legalista del silogismo que está criticando. Parte de esa sofisticación proviene del hecho de que envuelve la subsunción lógica bajo la distinción entre «lengua» y «lenguaje», es decir entre, por un lado, la lengua legislativa que - como un «diccionario» o una «gramática»- establece reglas convencionales de uso a ser empleadas en el lenguaje judicial y, por otro, este mismo lenguaje que es una especie de «habla» (o «reescritura» metalingüística) del primero (pues el juez es quien «dice el derecho») (cfr. 127, 156). Así, el principio de equidad es una «regla semántica sobre la formación del lenguaje judicial», sólo que no referida a la denotación (como el principio de legalidad, dirigido al legislador) sino a la connotación judicial. Una regla que prescribe que el juez connote «de la manera más precisa y penetrante los hechos denotados por la ley», comprendiendo en ellos «todas las circunstancias accidentales, específicas o particulares» (160).

Ahora bien, el juego de la distinción entre denotación y connotación, analizado de cerca, no responde realmente a reglas semánticas, sino en rigor a reglas sintácticas, es decir, lógico-formales. No se trata, dice FERRAJOLI frente a ARISTÓTELES, de que la ley incurra en «defecto» o «yerro» alguno ni que aparezca como «incompleta» cuando emerge un caso que queda fuera de la fórmula universal. Se trata «simplemente de la naturaleza lógica de la connotación (y la denotación) judicial respecto de la denotación (y la connotación) legal o del lenguaje respecto de la lengua» (161, subrayado mío). Es exclusivamente un nexo lógico el que comunica entre sí denotación y connotación. Así, todos los casos de robo son denotativamente iguales y al tiempo connotativamente distintos. Tendrán, dice FERRAJOLI, «caracteres accidentales necesariamente distintos, de modo que las dos tesis que enuncian su comisión expresarán contenidos informativos diferentes en relación con las diferentes e irrepetibles connotaciones de los dos hechos denotados ambos por la ley como «robos». Las distintas características accidentales de los dos robos, esto es, sus connotaciones específicas, forman precisamente el objeto de comprensión y de valoración en el juicio de equidad» (159). De manera que «el juez,

${ }_{11}$ Cfr. Ferrajoli, 1994: 88 y ss., 116 y ss. Algo que, no obstante, FerRAJOLI cree compatible con la asunción de que toda teoría comporta elecciones valorativas prácticas —el «papel normativo de la teoría», manifestado en la función crítica de la dogmática y la teoría del derecho-, lo que en su opinión permitiría la superación de la tesis ideológica «paleopositivista» de la neutralidad (id.: 109 y ss., 136). 
en un sistema de legalidad, connota de manera distinta lo que la ley denota, y denota de manera igual lo que la ley connota». No hay nada de misterioso en todo esto, dice FERRAJOLI: «Al connotar equitativamente un hecho concreto, el juez no corrige, integra, sobrepasa y ni siquiera interpreta la ley más de lo que yo corrijo, integro, sobrepaso o interpreto el significado de la palabra «mesa» definido por el diccionario cuando la uso para denotar la mesa sobre la que ahora estoy escribiendo y para connotar sus características específicas e irrepetibles que la hacen distinta de todas las demás mesas del mundo» (162).

En efecto, nada de misterioso tiene esta manera de entender la equidad. Simplemente sucede que la connotación (la valoración del caso a cargo del juez que ésta comporta) opera exclusivamente dentro del espacio cerrado por el juicio denotativo previo, juicio que a su vez queda agotado en la inclusión lógica de un individuo bajo una clase y que se mantiene pacíficamente idéntico, al parecer, en todos los casos. Es así como FERRAJOLI puede concluir que carece de sentido «contraponer legalidad y equidad, como si las dos cosas pudieran ir por separado o incluso una como alternativa a la otra», que «ni la legalidad es posible sin equidad ni la equidad [...] es posible fuera de la legalidad», que «todavía tiene menos sentido decir —como ARISTÓTELES y cuantos han copiado su pensamiento- que la ley es «incompleta» o que «el legislador omite y yerra» y concebir por ello la equidad como «correctivo», «integración» o «derogación del derecho formal», o como «lo justo que va más allá que la ley», según «el espíritu del legislador», el «derecho natural», la «conciencia social», la «discrecionalidad del juez» o similares»... y tantas y tantas otras afirmaciones que podrían reproducirse en el mismo sentido» (161).

Ahora bien, resulta evidente que esta manera de definir la equidad se limita a replicar el esquema formalista clásico al dar por sentado igualmente que la aplicación judicial del derecho - una vez determinados los hechos- es un simple asunto de inferencia deductiva (dabo mibi factum, dabo tibi ius). Ahora ello queda reforzado, como hemos visto, por la aceptación acrítica de la dicotomía hecho-valor plasmada en la combinación de una concepción descriptiva-observacional del lenguaje jurídico, el presupuesto metódico de la neutralización de los juicios de valor y un enfoque llanamente logicista del razonamiento judicial. Para comprobarlo, consideremos las dos siguientes aseveraciones de FERRAJOLI:

«La paradoja del carácter a la vez igual y distinto de los infinitos casos concretos subsumidos en una misma norma abstracta se deshace con sólo considerar que la igualdad de los casos se refiere a su denotación, mientras que la diferencia se refiere a su connotación; y que no se da una connotación sin denotación, ni a la inversa» (162).

«Todos los juicios sobre un mismo tipo de delito, aunque legalmente coextensos [...] nunca [son] equitativamente coextensos, sino cada uno siempre nuevo y distinto del precedente» (159).

En ambas se revela con nitidez la petición de principio a que antes nos referíamos en relación con la operación de denotación o subsunción: el postulado de que «el juez denota de manera igual lo que la ley connota» (es decir, que «los infinitos casos concretos subsumidos en una misma norma» son «iguales», que «todos los juicios son legalmente coextensos») tiene por misión sencillamente la elusión del problema central de la jurisdicción suscitado por la equidad, a saber: si y cuándo dos casos dis- 
tintos pueden considerarse subsumibles bajo la misma norma, si y cuándo dos hechos diferentes constituyen el mismo tipo de delito. Es decir, el problema de si la operación lógica de subsunción misma es legítima o está justificada en términos de aplicación de una regla. Y esta es evidentemente una operación que excede de la lógica formal por cuanto es de naturaleza esencialmente valorativa: depende de juicios de valor que sólo el aplicador puede poner mediante un razonamiento de naturaleza práctica. Tales juicios de valor son los que llevan a justificar precisamente por qué el caso presente es un «caso de» la regla general y abstracta (tal es la tarea de la calificación e interpretación del juez), algo que no puede determinarse exclusivamente por medios lógicos —como subraya HART, la lógica nada dice por sí misma acerca de la forma de clasificar casos particulares ${ }^{12}$ - sino que es una decisión práctica guiada por razones que trascienden la regla en aplicación y son por ello solidarias de una justificación externa o material acerca de su propia aplicabilidad y corrección. Pretender que estos juicios de valor — que constituyen el núcleo del razonamiento judicial— pueden ser reducidos a la relación de subsunción o justificación interna caso genérico-caso específico es dar por resuelto tautológicamente el problema de la equidad. El problema del formalismo y el antiformalismo no depende, por tanto, de «la naturaleza lógica de la denotación», sino que es esencialmente una cuestión del valor y de la justificación de la propia operación de denotación. Sólo puede resolverse, pues, desde una concepción no semántica ni sintáctica sino pragmática o constructiva del juicio, que es la adecuada a enunciados y razonamientos normativos y valorativos como son los judiciales, en los que - a diferencia de los razonamientos teóricos- es epistemológicamente insuprimible, no ya la referencia justificativa a valores prácticos, sino el compromiso en primera persona con ellos por parte de quien lleva a cabo dichos razonamientos.

Veamos ahora cómo se plantea la cuestión desde la perspectiva de un modelo pragmático de la jurisdicción — que pone los valores ético-políticos en primer planocomo el que está presupuesto en la teoría de la equidad de ARISTÓTELES.

\section{4.}

Lo que sigue es una reconstrucción de las ideas fundamentales de la teoría de la práctica judicial que se deducen de la noción aristotélica de epieikeia. Si tuviéramos que expresar lo esencial de esas ideas usando los conceptos del modelo ferrajoliano de jurisdicción que hemos visto hasta aquí, podríamos decir que la equidad aristotélica ilumina una relación que en ese modelo queda en la oscuridad, a saber: la relación entre el poder de connotación del juez y el poder de connotación del legislador. Si el lenguaje del juez es valorativo e interpretativo, lo es fundamentalmente porque se da en continuidad con el lenguaje legislativo. Esto implica entender lo que FERRAJOLI llama «denotación» (el vínculo central que según él conecta al legislador con el juez) como

12 «But just how in being a formalist does a judge make an excessive use of logic? It is clear that the essence of his error is to give some general term an interpretation which is blind to social values and consequences (or which is in some other way stupid or perhaps merely disliked by critics). But logic does not prescribe interpretation of terms; it dictates neither the stupid nor intelligent interpretation of any expression. Logic only tells you bypothetically that if you give a certain term a certain interpretation then a certain conclusion follows. Logic is silent on bow to classify particulars —and this is the beart of a judicial decision» (HART, 1958: 610). 
una relación no solamente lógico-lingüística (semántica o sintáctica) sino sobre todo pragmática pues de ella depende en realidad la normatividad de la ley. La dimensión de la jurisdicción como «poder» exige introducir desde el principio la idea de «práctica» para entender las relaciones legislador-juez en términos de relaciones entre dos prácticas institucionales diferentes pero coordinadas: la práctica de legislar y la práctica de aplicar la ley. Ambas — legislación y jurisdicción— son además prácticas «de segundo grado», es decir, se construyen sobre las prácticas sociales ordinarias de primer grado (externas al aparato institucional jurídico) respecto de las cuales tanto legisladores como jueces actúan a la luz de ciertos fines y valores envolventes del derecho.

La estructura de la práctica de la jurisdicción, entonces, tiene que ser analizada en tres dimensiones fundamentales:

i) la relación de la práctica jurisdiccional con la práctica social de primer grado. Aquí es donde se dan los «casos» o situaciones particulares que el juez ha de resolver, en relación con las cuales el juicio se determina, según FERRAJOLI, en las operaciones de «comprobación» y «connotación»;

ii) la relación de la práctica jurisdiccional con la ley o norma general emanada de la práctica legislativa. Es la «denotación» de FERRAJOLI, que en su modelo determina las dos anteriores;

iii) la relación de la práctica jurisdiccional con el legislador. Es la que queda presupuesta, sin tematizar, en el esquema de FERRAJOLI.

Esquematizando mucho, cabe decir que en el planteamiento aristotélico de la equidad el análisis de la práctica jurisdiccional sigue la dirección i) $\Rightarrow$ ii) $\Rightarrow$ iii). El juez lleva adelante un razonamiento práctico, una deliberación, que parte de un caso, se remonta a la ley y termina acudiendo (mediante la idea de «corrección») a la figura del legislador. Pero para entender adecuadamente esto es preciso analizar esa relación también en su sentido inverso, que es el que recorre, por su parte, la práctica legislativa: iii) $\Rightarrow$ ii) $\Rightarrow$ i). El legislador también lleva adelante un razonamiento práctico que va dirigido al juez para que mediante las reglas por él preestablecidas dé solución a los casos particulares.

La concatenación entre ambas prácticas (la de dictar y aplicar leyes) debe entenderse esencialmente, a su vez, en términos de una práctica colectiva más amplia de naturaleza esencialmente política: el proceso de la construcción del Estado ${ }^{13}$, de la organización política de una sociedad, proceso que se considera dirigido en función de ciertos valores o principios fundamentales: aquellos que están plasmados en la constitución. ARISTÓTELES deja claro que las leyes se hacen a la medida de la constitución política y no a la inversa y nos ofrece así la primera formulación sistemática del ideal del Estado de derecho, del «gobierno de las leyes» ${ }^{14}$. Es en esta práctica

13 Esta construcción es presentada a menudo por el Estagirita como una labor de construcción técnica, casi artesanal: vid. Política, III, 3, 1276b1-11; IV, 1, 1288b19-21; VII, 4, 1326a35-38. Pero es claramente una metáfora que ilustra más el carácter constructivo-valorativo del derecho y la política que su estatuto epistemológico. También DwORKIN $(1986 ; 2011)$ y NINO (1994) utilizan metáforas artísticas para ilustrar el papel interpretativo que la práctica jurídica cumple dentro de la moralidad política o su inmersión en una práctica política.

14 «Donde no imperan las leyes no hay constitución» (Pol., IV, 4, 1292a32). Cfr. Pol., II, 9, 1269a32; III, 16, 1287a25 y ss. Vid. BODÉÜs, 1993: 74; Miller, 1995: 157 y ss. 
envolvente político-moral donde debe buscarse tanto la razón de ser de las leyes (de la institución legislativa) como de su proceso pautado de aplicación (de la institución jurisdiccional).

Así, por un lado, las leyes son aquellas normas que establecen los cursos de acción aplicables a todos los individuos en cuanto ciudadanos (no ya miembros de comunidades morales precursoras de la comunidad política) y que promueven por tanto aquellos principios y valores de índole político-moral que incumben al bien público ${ }^{15}$. Estos valores representan una cierta concepción de la justicia reflejada en cada constitución histórica que desde entonces preside el desarrollo de la acción pública o estatal, es decir, las operaciones de legisladores, jueces y funcionarios (quienes deben darle ejecución, dice ARISTÓTELES, «como si fueran obreros manuales» ${ }^{16}$, es decir, con sometimiento a las leyes). El decurso de este entramado de prácticas públicas en el marco del Estado queda así vinculado a la virtud de la justicia, virtud que ARISTÓTELES analiza fundamentalmente en términos del cumplimiento de la idea de igualdad dentro de las prácticas sociales de primer orden tanto en lo que respecta al reparto de bienes (justicia distributiva) como a la reparación de ilícitos (justicia correctiva) ${ }^{17}$.

Para que las leyes puedan desempeñar ambas funciones —aplicarse a todos los ciudadanos y promover esos valores colectivos- ARISTÓTELES subraya con insistencia que deben formularse como normas universales (katholou), es decir, estrictamente generales (a base de clases lógicas — de sujetos, acciones, circunstancias- que puedan ser predicadas de las situaciones particulares por medio de la saturación de variables de individuo ${ }^{18}$. Esta generalidad es así una exigencia vinculada a la justicia no sólo en su sentido formal (la igualdad de trato o isonomia) sino también - y sobre todoen su sentido material: la consecución social efectiva de los valores en cuestión. Y es aquí donde entra en escena la jurisdicción. Implantar en la práctica social los valores de justicia política que la legislación pretende propagar (la igualdad, pero también la eleutheria o libertad, así como los valores de moralidad que representan las restantes virtudes ${ }^{19}$ ) exige articular una práctica decisoria continuada e institucionalmente autónoma de aplicación de las leyes a cargo de una instancia intermediaria entre ambas: esa es la práctica judicial ${ }^{20}$.

De este modo, tanto la legislación como la jurisdicción se conciben desde un principio como empresas prácticas, no sólo cada una de ellas independientemente sino también y sobre todo en su relación interna de continuidad. Esta continuidad viene dada esencialmente por el proceso de propagación de los principios y valores articulados en la constitución: no se trata solamente de praxis sino de eupraxia («acción buena»), no sólo de leyes sino de eunomia («buenas leyes»), no sólo de orden, perdurabilidad y estabilidad políticas sino de eutaxia («buen orden») ${ }^{21}$. Las propias constituciones políticas son ordenadas por ARISTÓTELES en función de su corrección axiológica

15 Cfr. Ét. Nic., II, 1, 1103b3-4; X, 9, 1180 a32 y ss.

16 Ét. Nic., VI, 8, 1141b28-29.

17 Cf. Ét. Nic., V, 3 y 4; Pol., III, 1282b23-30.

18 Ét. Nic., V, 7, 1135a5-8.

19 Ét. Nic., V, 3, 1131a25-29; V, 1, 1129b20-26; V, 2, 1130b18-26.

20 Sobre el juez como «término medio» o «mediador» que «restablece la igualdad»: Ét. Nic., V, 4, 1132 a19 y ss; como «guardián de la justicia», es decir, del «bien para otro [pros heteron]»: V, 6, 1134b1 y ss.

21 Pol., III, 9, 1280b5-6; IV, 4, 1326a29-30. 
por referencia al criterio del interés colectivo ${ }^{22}$ (e incluso llega a hablar de «la mejor constitución por naturaleza» en el célebre pasaje donde distingue entre justicia legal y justicia natural) ${ }^{23}$.

La idea aristotélica de prudencia (phronēsis) encierra toda una compleja epistemología del valor que, por cierto, comparte algunos supuestos con la epistemología positivista, si bien para extraer de ellos consecuencias diametralmente opuestas. Afirmar que legislación y jurisdicción son empresas «prudenciales» - y por ello «prácticas»significa subrayar que su estatus epistemológico es el de actividades o instituciones cuyo objeto es precisamente realizar valores prácticos: aquellos valores ético-morales y políticos que condensamos en la idea de justicia. En este sentido, por decirlo con ALEXY, ambas exhiben una pretensión de corrección desde la cual deben ser juzgadas críticamente todas sus producciones, es decir, en la medida en que satisfagan o no tal pretensión, que para empezar ellas mismas asumen como autojustificación. Esto coloca al valor en el centro de la práctica jurídica, por decirlo ahora con DwORKIN, como aquello que le dota de sentido y hace de ella una práctica interpretativa que exige una determinada actitud crítica.

Así, la legislación es una institución que persigue la implantación de ciertos valores en la esfera de la práctica social en función del marco constitucional respectivo («hacer buenos a los ciudadanos haciéndoles adquirir ciertos hábitos», dice ARISTÓTELES ${ }^{24}$, en palabras que no deben entenderse en un sentido únicamente «perfeccionista»), valores que se traducen en su caso en una única decisión: la producción de una regla o conjunto de ellas. El razonamiento legislativo tiene un lugar preeminente porque la composición de valores y principios constitucionales que se plasma en cada ley implica la deliberación política más prolongada y de consecuencias más importantes, dado que ese único acto está destinado a traducirse en el futuro en una multiplicidad indefinida de decisiones en cascada: ARISTÓTELES la llama por ello «arquitectónica» y «prospectiva [peri mellontōn] $\gg^{25}$. No es, en efecto, suficiente con que existan las leyes como normas generales para implantar la justicia a la escala de una sociedad política: es preciso además asegurar que los valores que ellas promueven se vean materializados en todas y cada una de las situaciones que esas normas contemplan. Esa es la razón de ser de la jurisdicción: producir una sucesión de decisiones singulares y recurrentes en aplicación de las reglas legislativas que conduzcan a verificar aquellos balances de valores que las justifican. De ahí la continuidad entre ambas instituciones en un sistema de «gobierno de las leyes». La jurisdicción es la prolongación práctica de la legislatura y sus decisiones se imputan al derecho legislado como norma política impersonal expresiva de valores colectivos que realizan una cierta concepción del bien público. La iuris dictio es, entonces, iuris prudentia porque, efectivamente, su función es llevar a cabo una deliberación localizada en un caso particular (en cada caso relevante a la luz de las leyes), siempre que se demande una solución por parte del derecho a raíz de las disputas y conflictos sociales («casos presentes y determina-

22 Pol., III, 9-13. Lo «correcto» (orthon) ha de entenderse como lo «igual» (isôs), y lo «igualmente correcto» (isôs orthon) es «aquello que se ordena al beneficio de toda la comunidad (poleôs holès) y de los ciudadanos (koinon to tôn politôn)».

23 Ét. Nic., V, 7, 1135a5.

24 Ét. Nic., V, 2, 1103b3-4.

25 Ét. Nic., I, 1, 1094a14; 2, 1094b5; Retórica, I, 1, 1354b8-9. 
dos», dice ARISTÓTELES ${ }^{26}$, por contraste con las leyes generales y abstractas, y por ello indeterminadas). Esa solución tiene que ser recabada por el juez retrospectivamente, tanto en lo que respecta a los hechos y circunstancias del caso - que son siempre segmentos pretéritos de práctica social— como en relación con los criterios normativos para su dictado, que no son sino los preestablecidos por la ley. En ARISTÓTELES encontramos, pues, ya formulados con toda claridad los que FERRAJOLI llama principios de estricta legalidad y estricta jurisdiccionalidad. También el juicio se centra en las exigencias de verificabilidad (denotación jurídica y comprobación fáctica) del modelo ferrajoliano ${ }^{27}$. Así, ARISTÓTELES asume que la organización política de la justicia en términos de un Estado de derecho exige el establecimiento previo de estándares de conducta generales por la institución legislativa y que la institución judicial está regida estrictamente por el deber de aplicar y hacer cumplir esos estándares legales. Legislar consiste en anticipar selectivamente determinados cursos de acción mediante tipos generales erga omnes — sin acepción de persona - que se fijan por deliberación a partir de las situaciones precedentes de la práctica social y en vista de ciertos valores, asignándoles pro futuro consecuencias jurídicas predeterminadas que envuelven la coacción estatal. Es importante advertir el énfasis que ARISTÓTELES pone sobre la temporalidad de la práctica jurídica como práctica de segundo orden que se construye en términos de estados antecedentes y consecuentes de la práctica social primaria. Pues esta temporalidad determina enteramente la relación interna entre legislación y jurisdicción que está en la médula de la tesis de la equidad. El legislador anticipa tipos de acción, pero lo que no puede anticipar es cada caso singular: la determinación jurídica de éstos debe correr a cargo de una instancia posterior, deferida, y esto es lo que hace prácticamente necesaria a la jurisdicción ${ }^{28}$. Ahora bien, lo esencial es que ello no sólo incumbe a la verdad (a la comprobación fáctica) sino también a la denotación, la connotación y la disposición: es decir, a la valoración jurídica del caso. ARISTÓTELES deja claro que la exigencia que vincula el razonamiento del juez a la legalidad no solo no es incompatible, sino que es en realidad indesligable, de la exigencia de equidad como justicia, que demanda de él juicios de corrección de la ley. ¿Qué quiere decir ARISTÓTELES con tal cosa? ¿Qué significa «corregir la ley»?

No es difícil advertir que ello tiene mucho que ver justamente con la prominencia que exhiben los valores como elementos esenciales articuladores del conjunto de la práctica jurídica y, por consiguiente, con la centralidad que las operaciones de evaluación del juez pasan a tener dentro de la práctica jurisdiccional. Tenemos aquí, por lo tanto, dos epistemologías del valor en liza. Una, la adoptada por FerRajoli y el

26 Ret. I, 1, 1354b7-8.

27 Exigencias que tienen su correlato en el principio dirigido al legislador de formación de sus normas en un lenguaje taxativo y verificable (dicho de otro modo: que sea un lenguaje de reglas, o inmediatamente relativo a cursos de acción).

28 Así, señala ARISTÓTELES: «corresponde a las leyes bien dispuestas determinarlo por sí, en cuanto sea posible, todo, y dejar a los que juzgan lo menos posible [...] es preciso hacer al juez árbitro de las menos cosas posibles [...] pero es forzoso que a los jueces se les deje la decisión sobre si algo ocurrió o no [...] o si es o no es, pues no es posible que eso lo prevea el legislador»; «Puesto que muchas veces el acusado reconoce haberlo hecho, pero no está de acuerdo sobre la calificación o acerca del delito a que la calificación se refiere; así, admite haber cogido algo, pero no robado, y haber golpeado primero, pero no ultrajado, y haber tenido trato con una mujer, pero no haber cometido adulterio, [...], por eso sería necesario definir acerca de esto qué es robo, qué ultraje, qué adulterio, de manera que si queremos mostrar si hay o no hay tal delito, podamos declarar el derecho»(Ret., I, 1, 1354a32-1354b17; I, 13, 1374a1 y ss.). 
positivismo jurídico, que asume la naturaleza irracional o praeterracional de los juicios de valor y pretende desterrarlos a toda costa del razonamiento judicial presentándolo como un razonamiento teórico o cognoscitivo (y en tal sentido lo aproxima tendencialmente a la racionalidad de la técnica o a la ciencia). La otra, la aristotélica (y también la postpositivista o argumentativa), que asume desde el principio la presencia necesaria de los juicios de valor en la jurisdicción (pues el nexo de ésta con la legislación se da justamente en términos de coherencia axiológica) y pone énfasis no ya en intentar neutralizarlos, lo cual es por demás imposible, sino en la justificación racional de los mismos, aproximándose así a la argumentación práctica de carácter moral o político: a lo que ARISTÓTELES llama praxis, que sería aquel nivel de racionalidad —el propio de las instituciones de la politike, cuya función es precisamente salvaguardar ciertos valores político-morales- en que se mantiene la institución del derecho.

La tesis de fondo del modelo aristotélico es, pues, que la jurisdicción es ab origine una empresa deliberativa de consistencia esencialmente valorativa. Que sea una forma de prudencia, de razonamiento práctico, tiene un sentido epistemológico crítico: significa que no puede ser presentado como un razonamiento teórico, es decir, como una empresa cognoscitiva (o recognoscitiva). Eso sería tanto un error metodológico (que presenta a la racionalidad jurídica como lo que no es: una técnica o una ciencia), cuanto simplemente un enmascaramiento ideológico (que pretender dotar a sus justificaciones de un tipo de objetividad del que necesariamente carecen: por ejemplo, presentando como inferencias deductivas, objetivas, lo que no son más que decisiones prácticas dependientes de evaluaciones subjetivas que como tales deben ser justificadas). Pero que la racionalidad prudencial carezca de objetividad científica no significa - y este es el segundo punto en que la epistemología aristotélica y la positivista se alejan decisivamente- que carezca de toda objetividad. Ésta tiene que ver justamente con la que quepa atribuir a la justificación o corrección que corresponde a los juicios de valor.

No es posible reproducir aquí la compleja argumentación que en ARISTÓTELES certifica el cerrado contraste entre epistēmē y phronēsis, llevándole por un lado a distanciar definitivamente entre sí racionalidad científico-teórica y praxis político-moral, y por otro a mantener, sin embargo, una concepción objetivista de la razón práctica que hace uso de la idea de corrección o verdad ${ }^{29}$. Baste con indicar que la racionalidad teórica y la práctica se hallan conforme a esta epistemología asimétricamente relacionadas: la acción implica conocimientos así como la epistēmē tiene conexión interna con la praxis (por ejemplo en la dialéctica y en la técnica), pero el conocimiento pasa a un segundo plano en el mundo de la práctica (en la moral y la política) y la acción pasa a un segundo plano en el conocimiento teórico-científico (por eso éste es objetivo y universalizable). La praxis consiste en el ejercicio de la acción con arreglo a valores (las virtudes) que comprometen al individuo en cuanto que tal individuo agente (y en la justicia, en su relación interpersonal con otros), mientras que en el conocimiento estricto se siguen reglas impersonales y objetivas como las que la ciencia y la técnica descubren y ponen en obra en la naturaleza (de ahí que la verdad de la teoría se defina en virtud de la independencia respecto de valores prácticos). Naturalmente, esto no significa que en el razonamiento práctico no sean relevantes y operativos fragmentos

29 Remito a VEGA, 2013b: 2-6. 
de razonamiento teórico. Una buena prueba de ello es precisamente el papel de la verdad, de los valores epistémicos, en el razonamiento judicial. Ya en el ámbito moral la prudencia es definida por ARISTÓTELES como disposición verdadera determinada por la razón: es una virtud «dianoética», es decir intelectual o relativa al conocimiento ${ }^{30}$. Esto se mantiene en la juris-prudencia, en el razonamiento prudencial del juez. Pues - recordemos el texto antes citado de la Retórica - el juicio presupone la verdad de las premisas fácticas y normativas en las que se basa, es decir, la existencia cierta de determinados hechos y de normas legislativas que el juez no pone y a las que debe ajustar su razonamiento.

Pero es completamente mixtificador de la estructura del razonamiento judicial —y, en general, práctico- - presentar esa verdad (jurídica y fáctica) como un valor que (al modo de la verdad teórica de la ciencia) actúa en él al margen de valores prácticos, como si pudiera convertirse en un razonamiento neutral, técnico o científico, excluyente de los juicios de valor prácticos y por tanto puramente «cognoscitivo» en el sentido ferrajoliano. La situación es exactamente la inversa: la verdad resulta aquí relevante en función de una institución orientada a producir decisiones exclusivamente en busca de la consecución de valores prácticos o de justicia, esto es, decisiones justificadas moral o políticamente. Si la jurisdicción es una «práctica de segundo grado» es porque ciertos sujetos deben decidir respecto de otros sujetos a propósito de la adopción de consecuencias prácticas relativas a la coacción estatal ${ }^{31}$. Son, por lo tanto, valores eminentemente prácticos, político-morales, los que determinan la formulación de las reglas legislativas en las que se prescriben las condiciones en que debe emplearse el aparato coactivo público. De manera que tanto el deber de decidir (prohibición del non liquet) como el de motivar (argumentar la decisión sobre el material legislativo), que establecen su vinculación institucional con la legislatura, son la expresión más clara de que la función de la jurisdicción no es sino la de asegurar la materialización de esos valores en la práctica (como «función de garantía por antonomasia») ${ }^{32}$. La continuidad entre el juez y el legislador, además de lógico-lingüística, es pragmática y axiológica: lo que el legislador le encarga al juez es precisamente que valore, que formule juicios de valor que le lleven a una decisión práctica justificada por respecto a esos valores. Por supuesto, las valoraciones del juez son deferidas respecto de las del propio legislador bajo un sistema de gobierno de las leyes: las decisiones judiciales sólo pueden responder a los balances de valores expresados en las reglas legislativas que son precisamente aquellos que el legislador pretende transportar a las prácticas sociales por la mediación de tales reglas y, por tanto, por la mediación de los jueces, quienes tienen por misión hacerlos presentes en dichas prácticas. Pero que esas reglas deban ser incorporadas como premisas o fundamentos de la decisión demuestra que son sus valores subyacentes aquello que orienta y justifica a la propia institución judicial, de modo que aunque en principio la decisión parezca excluir la propia deliberación valorativa del juez en primera persona sobre los mismos, no puede producirse al margen de al menos juicios de valor deferidos (retrospectivos, como dice ARISTÓTELES) que supongan la adhesión por su parte a esas reglas y a las decisiones adoptadas como consecuencia de su aplicación

30 Ét. Nic., VI, 5, 1140b5, 20.

31 La jurisdicción, dice FERRAJOLI, es «una actividad que tiene por objeto otra actividad: [...] un acto sobre un acto» (2011: I, 832).

32 FERRAJOLI, 2011a: II, 200; I, 827 y ss. 
(es decir, al seguimiento o imposición de los cursos de acción en ellas prescritos en relación con el caso). Estos juicios de valor - los «juicios de adhesión normativa» de NINO o los «juicios evaluativos secundarios» de DWORKIN ${ }^{33}$ - tienen que ser puestos por el razonamiento del juez como condición de posibilidad de la propia práctica de la jurisdicción. La motivación, entonces, no convierte a la actividad judicial en independiente de valores (como si fuese una actividad técnica o científica), sino todo lo contrario: la vuelve una praxis inmediatamente comprometida con esos valores. Siendo el propio lenguaje legislativo necesariamente valorativo - connotativo- puesto que la práctica de legislar o dictar reglas consiste en redefinir las prácticas sociales a fin de reorientarlas selectivamente en función de valores plasmados en las «generalizaciones atrincheradas» a base de las cuales se elaboran (SCHAUER, 1991: 21 y ss.), la motivación o argumentación judicial tiene igualmente un carácter interpretativo y está valorativamente involucrada.

Ello deriva del hecho siguiente: si la construcción deliberativa de los predicados fácticos y normativos a base de los cuales el legislador elabora sus reglas no es independiente de la implementación causal de los estados de cosas correspondientes a los valores que son su justificación, entonces tampoco puede serlo su actualización ulterior en la deliberación judicial. Existe una relación intencional o teleológica entre la selección de las propiedades que forman los «casos genéricos» de las reglas —selección que responde a juicios de valor en la medida en que incluye o excluye como relevantes unas $\mathrm{u}$ otras propiedades- $\mathrm{y}$ sus consecuencias jurídicas, tal como éstas van a ser implementadas por la jurisdicción. Dicha relación intencional o pragmática de continuidad entre legislación y jurisdicción ha sido explorada por el iuspositivismo ${ }^{34}$. Ella explica: i) que el literal sea el primer criterio autoritativo de interpretación jurídica (sin dejar de ser teleológico), dado que el nexo entre legislador y juez se da a través de un medio lingüístico: el texto de la ley, que responde a «intenciones comunicativas», expresa él mismo intenciones prácticas, está orientado a «intenciones ulteriores» (further intentions, en la terminología de MARMOR) que a su vez dependen causalmente de «intenciones en cuanto a su aplicación» futura (application intentions) ${ }^{35}$; ii) que el llamado «criterio teleológico» sea genérico a todos los demás o «transcategorial» (MACCORMICK y SuMMERS, 1991: 522); y iii) que el segundo deba entenderse en términos correctivos del primero: es decir, que aquello que se considera «intención del legislador» sea en realidad un constructo valorativo del juez en virtud del cual se determina qué es lo que relevantemente queda dentro o fuera del texto de una regla a la luz de los valores que constituyen su justificación ${ }^{36}$. Por ello, si el cometido de la jurisdicción es justamente

33 NinO, 2006: 52 y ss., 140; DwORKIN, 1986: 66 y ss.

34 Dice RAZ, por ejemplo: «Carece de sentido conceder a cualquier persona o cuerpo un poder legislativo a menos que se asuma que el derecho que dictan es el derecho que tienen la intención de dictar» (RAZ, 1996: 258).

35 «Las razones para remitirse a las intenciones de los legisladores sólo pueden derivarse de las razones para cumplir con las autoridades legislativas en primer lugar» (MARMOR, 2001: 90). Sobre la distinción entre further intentions y application intentions, $c f r$. MARMOR (2005: 127 y ss.).

36 De este modo, la identificación y atribución de intenciones al legislador como parte de la interpretación judicial presenta un carácter reconstructivo cuyos criterios de corrección ya no pueden hallarse en la propia legislación (o en las convenciones del momento de la producción de la ley) sino en consideraciones de coherencia a la luz de valores político-morales llevadas a cabo (retrospectivamente) por el intérprete. Sólo así puede decirse que no hay una incompatibilidad necesaria entre la dimensión intencional (en el sentido de RAZ 
«verificar» de modo recurrente la relación entre antecedentes o condiciones de aplicación y consecuentes o efectos jurídicos tal como está codificada en los textos legislativos, para así establecer esa continuidad intencional de la que hablamos, la decisión judicial tiene que introducir necesariamente juicios de valor y dicha verificación debe entenderse como justificación coherente. Es decir, supone una interpretación práctica o constructiva en la que se trata de hacer prevalecer eficazmente los valores que dan sentido a los textos a partir de una deliberación creativa y productiva acerca de su mejor encaje en la práctica (tanto en la práctica institucional jurídica —en la historia legislativa y jurisprudencial - como en la práctica social primaria).

Esto hace que la construcción de las premisas legislativas y fácticas del razonamiento judicial, aun cuando deba considerarse una operación presidida por el valor de verdad, está lejos de poder reconocerse como solamente «cognoscitiva». La identificación de las normas aplicables, más que un juicio de hecho llevado a cabo por el aplicador, encierra un juicio de coherencia pragmática (que, como defendió NINO, conduce finalmente a ver la noción de «validez» como concepto-puente justificativo: cfr. ROCA, 2005: 190 y ss.). Lo que el derecho es (o dice) no excluye sino que incluye las evaluaciones a cargo del juez, en la medida en que se hace equivalente a lo que se sigue prácticamente de él ${ }^{37}$. El reconocimiento del legislador (de la ley como vinculante) no puede ser sólo fáctico sino también axiológico: sin este elemento no cabría siquiera hablar de él como «autoridad» que no solamente detenta un poder de hecho sino que reclama aceptación en relación con sus normas en función de determinados objetivos valiosos a los que éstas apuntan. La actividad calificadora e interpretativa no es, pues, reducible simplemente a «denotación» lógico-lingüística, subsuntiva o clasificatoria por el juez de lo connotado por el legislador: si los términos y predicados de las reglas legislativas se refieren a fragmentos de prácticas humanas (a toda la constelación de la acción: intenciones, deseos, percepciones, resultados, consecuencias, valores, etc.), esa denotación deviene necesariamente valorativa porque la sola identificación y relevancia de aquéllos a la hora de calificar e interpretar los hechos juzgados requiere de juicios de valor que no están ni pueden estar contenidos en las propias reglas, sino que deben ser puestos por el juzgador para que éstas puedan ser aplicadas. De ahí que dudosamente quepa encajar la quaestio facti y la quaestio iuris en el dualismo hecho/ valor, como si ambas cayeran en exclusiva del lado de los «hechos» (el hecho de la ley y los hechos del caso). En realidad la separación entre ellas se da fracturada en múltiples planos donde las cuestiones de calificación, relevancia, interpretación y prueba, como ha mostrado MACCORMICK, se entretejen en la deliberación y dependen esencialmente de evaluaciones de diverso orden ${ }^{38}$.

\footnotetext{
y MARMOR) y la dimensión valorativa (en el sentido de DwORKIN) de la interpretación jurídica: al respecto, $c f r$. LIFANTE VIDAL, 1999: esp. 189 y ss.

37 Como lo expresa ATRIA (1999: 83), «para establecer qué es el derecho debe previamente establecerse qué debe ser el derecho».

38 El propio FERRAJOLI ha de reconocer esto al afirmar que la lengua legislativa funciona como «un sistema de esquemas interpretativos de tipo selectivo mediante los que recorta los únicos elementos del hecho que reputa penalmente "relevantes" e ignora todos los demás» (58) y que por ello la motivación e interpretación de la proposición de derecho «como hoy es pacíficamente admitido, no es nunca una actividad solamente recognoscitiva, sino que siempre es el fruto de una elección práctica respecto de hipótesis interpretativas alternativas» (39, subrayado mío). Lo mismo sucede con la motivación fáctica, la prueba, de la que concede asimismo que «no es en realidad una actividad solamente cognoscitiva, sino que siempre forma la conclusión
} 
Es importante advertir las razones epistemológicas que hacen que incluso la verdad que rige la motivación y argumentación fáctica no pueda hacerse encajar en el molde de los «hechos» positivistas construidos a imagen y semejanza de la ciencia o la técnica. Ello deriva sencillamente de que la prueba no versa sobre hechos observables directos sino que es la reconstrucción de eventos prácticos acaecidos en el pasado. De ahí las dificultades de aplicación de la idea de verdad científica como correspondencia, sujeta a verificación y refutación en condiciones de repetibilidad y control experimental. Lo que el juez debe considerar probado es en realidad el resultado de la interpretación de signos: de las fuentes o medios de prueba (los únicos hechos presentes observables), muchas veces no existentes antes e independientemente del proceso, sino construidos artificialmente en éste (FERRAJOLI subraya que el proceso es el único caso de «experimento histórico» ${ }^{39}$ ) y la mayoría consistentes en piezas de conocimiento práctico ordinario: testimonios, interrogatorios, reconocimientos, careos, pericias, atestados policiales, denuncias...). Pero no es sólo que el razonamiento probatorio del juez tenga que situarse epistémicamente en el mismo nivel fenomenológico — no impersonal— de la práctica ordinaria de primer orden, como sucede con el historiador, el periodista o el detective. Comparte además con ellos que estas prácticas son auto-justificativas, al ir referidas ya internamente a valores [WEBER, 1904 (1973)], de forma que los hechos llegan al juez ya pre-interpretados desde hipótesis enfrentadas, es decir, en términos de conflicto social formalizado desde las propias normas jurídicas. Y aquí radica la diferencia decisiva con esos otros géneros de investigación: la interpretación judicial de los hechos no se detiene en la búsqueda de la verdad fáctica ni persigue ésta por sí misma - no es una empresa teórica — sino que obedece al fin primordial de establecer una decisión que ponga término al conflicto cuya justificación va a presumirse autoritativamente como verdadera (res iudicata pro veritate habetur). Es decir, se trata de una verdad como corrección práctica. Que ésta deba poder fundarse en razones técnicocientíficas y, por tanto, responder irrenunciablemente a un ideal de objetividad teórica (distintivo de los sistemas jurídicos racionalistas, o del racionalismo que implica el derecho como sistema de control de la conducta en función de reglas), no impide que se trate de un valor antes político-moral que epistémico, esto es, un valor en última instancia práctico y no teorético. Para decirlo rápidamente: la verdad es una condición necesaria de la justicia. O en palabras del propio FERRAJOLI: «La investigación judicial no es una búsqueda puramente intelectual, sino el presupuesto de decisiones sobre las libertades de los ciudadanos» (154). Así se desprende del análisis del conjunto de reglas y garantías que disciplinan el curso práctico del proceso judicial mismo, organizado como un debate racional en el que se reproduce de vivo el conflicto social en

\footnotetext{
más o menos probable de un procedimiento inductivo cuya aceptación es a su vez un acto práctico que expresa un poder de elección respecto de hipótesis explicativas alternativas» (39, subrayado mío). Todo ello remite a lo que el autor italiano llama «interpretación operativa» del juez. Entre la prueba (del acto ilícito o inválido objeto de juicio) y la interpretación operativa (de la norma violada) habría, dice FERRAJOLI un «nexo de implicación» (2011a: I, 833). Ese nexo es evidentemente un razonamiento práctico y no un razonamiento teórico como el autor italiano lo presenta: así como la «ilicitud» o la «invalidez» de un acto no son sino juicios de valor, su formulación por el juez está lejos de poder presentarse como una «constatación», «un acto declarativo o cognitivo» (2011a: I, 832).

39 Podría hablarse de «efecto Rashomon» (por analogía con el uso de esta expresión en antropología) para describir este peculiar rasgo del proceso según el cual se convierte él mismo en la reconstrucción singular de ciertos hechos singulares que de otro modo no serían objeto de reconstrucción y valoración (y a los que muchas veces sólo se tiene acceso a través del propio proceso judicial).
} 
términos de intercambio argumentativo-dialéctico (otra manifestación eminente del carácter de estricta praxis de la racionalidad jurídica ${ }^{40}$ ).

Ahora bien, si la verdad es una condición necesaria de la justicia, no es sin embargo una condición suficiente. Esto significa que no puede ser vista como una garantía epistémica que sirva por sí sola para neutralizar las valoraciones del juez (ni, menos aún, como criterio exclusivo de corrección práctica). En efecto, incluso cuando hablamos de pruebas científicas basadas en parámetros objetivos (por tanto, de la incorporación al razonamiento probatorio inductivo de elementos resultantes de razonamientos teóricos rigurosos) la verdad tampoco se convierte en el valor último o decisivo. Aunque el margen de elección subjetiva entre hipótesis probatorias se haya reducido hasta un grado máximo (pensemos en pruebas de ADN en el ámbito civil o penal), el juez sigue teniendo que adoptar una decisión práctica (prudencial). Debe construir el juicio de imputación (la individualización de la culpabilidad) que es, primero, estrictamente un juicio de valor (en tanto consiste en la atribución de una desviación normativa) y, segundo, un juicio de valor indeducible de ese razonamiento teórico: sólo se sustenta en una toma de posición del juez con base en las normas jurídicas cuyos valores subyacentes (los bienes jurídicos en este caso) pretende hacer imperar en el caso mediante una deliberación específica. La reducción de este razonamiento a un algoritmo lógico, técnico o científico, que suprimiera su dimensión de valor resulta, pues, epistemológicamente imposible (pues ello equivaldría a disolver su normatividad).

Y así como la verdad es en el derecho un valor que no puede ser establecido por adelantado en la instancia legislativa, sino sólo por el razonamiento judicial singularizado en cada caso (FERRAJOLI rechaza con este argumento el sistema de prueba legal o tasada), lo mismo sucede con la justicia. Esta es la idea de fondo de la equidad aristotélica. En efecto, ARISTÓTELES asume que «es imposible establecer lo justo en términos universales» ${ }^{41}$ precisamente porque la justicia es un valor práctico (no teórico) que debe ser logrado en una colección indefinida de situaciones prácticas cambiantes e inciertas: es sólo el razonamiento prudencial el que puede someterlas a regla verifican-

40 Las reglas de la carga de la prueba y el contradictorio, oralidad e inmediación, exclusión e inadmisibilidad de la prueba, derecho de defensa y paridad de las partes, publicidad, imparcialidad e independencia del juez, tienen todas ellas sin duda fundamentos lógico-epistemológicos en tanto se encaminan a garantizar la objetividad, la eliminación del error (la falsedad o el engaño) y la reducción de la incertidumbre. Así, FERRAJOLI considera que el fundamento de estas reglas es más «lógico» que «jurídico», que su valor normativo proviene más de los principios de la lógica (en sentido amplio, comprensivo de la metodología inductiva) que del derecho: en ese sentido, dice, «no es necesaria, aunque sería fuertemente deseable, su explícita formulación legislativa» (153). Ahora bien, a continuación señala que si no estuviesen contempladas en las reglas del derecho procesal, una decisión que desatendiese esas reglas sería «inadmisible», pues sería una «causa de ilegitimidad, y no sólo de irracionalidad, de las decisiones injustificadas conforme a ellas». Con esto viene a reconocer que el fundamento último de todas esas reglas epistémicas es efectivamente moral y no epistémico: que son más reglas del derecho que de la lógica, entendiendo el derecho como una empresa orientada por valores prácticos. Sólo así puede entenderse la funcionalidad del principio in dubio pro reo en la presunción de inocencia, que FERRAJOLI define como «norma de clausura» sobre la decisión de la verdad fáctica que impide la condena en presencia de prueba insuficiente o de contrapruebas no refutadas. La única justificación de esta norma es la evitación del error judicial, el cual aquí no cuenta solamente como un error epistémico, una falsedad, sino como un disvalor, una injusticia: la que supone violar el principio moral de que ningún inocente sea castigado (el principio que justifica precisamente el derecho penal mínimo). Como luego veremos, este principio no opera solamente en la premisa fáctica sino también en la calificación e interpretación normativa y ello es precisamente una manifestación de la equidad.

${ }^{41}$ Constitución de los atenienses, 9 (a propósito de las leyes de Solón). 
do que en la serie de todas y cada una de ellas dicho valor va a verse satisfecho (esto es: la congruencia de la práctica, asegurada). Del mismo modo que establecer la virtud «en general» no es suficiente ${ }^{42}$, tampoco podría ningún legislador garantizar que el criterio general resultante de su deliberación - la ley_ vaya a resultar correcto en todas y cada una de las futuras situaciones en que debe ser aplicado. No es, por tanto, sólo un problema de límites del lenguaje: la textura abierta o indeterminación de las reglas jurídicas proviene justamente del hecho de que éstas (a diferencia de las reglas teóricas del conocimiento, regidas por el valor de verdad) están mediadas por valores prácticos como los que tienen que ver con la justicia, que son relativos a la acción de otros sujetos (pros heteron) ${ }^{43}$ y que tienen que ser salvaguardados y amparados por la decisión en primera persona del juez, que es su «personificación» y «guardián», o sea, su garante. De manera que la corrección de una regla práctica -incluso cuando ha sido correctamente deliberada en la instancia legislativa - sólo puede ser asegurada $a$ posteriori, mediante un discurso específico de aplicación que determine cómo ha de ser correctamente aplicada a la situación dada, incluyendo la posibilidad de que sea abandonada para dar lugar a una nueva regla. Esta es la única forma en que la universalidad lógica (el juego de lo general-particular) puede ser un criterio de racionalidad apropiado también en la esfera de la praxis.

Esto supone que también la denotación del juez, la operación mediante la que realiza la clasificación o subsunción de los hechos bajo las fórmulas legislativas, está necesariamente condicionada al ejercicio de evaluaciones in casu a su cargo. Estas evaluaciones son internas a la denotación, y no externas como afirma FERRAJOLI (y lo son sencillamente porque en el propio lenguaje legislativo lo connotativo y lo denotativo no están disociados) ${ }^{44}$. Pues, como hemos dicho, es una apreciación o evaluación lo que lleva a considerar relevante una norma: el juicio de relevancia no puede ser más que un juicio axiológico, esto es, una valoración formulada y justificada racionalmente por referencia a esa norma como criterio o razón para actuar. Dicho de otra manera: es la connotación que el juez realiza respecto de cada caso la que determina su denotación del mismo. Pero expongámoslo de nuevo en el vocabulario aristotélico. El juez parte, dice ARISTÓTELES, de casos «presentes y determinados», que surgen de manera «imprevista» ${ }^{45}$ en la práctica social y por ello debe remitirse a él su evaluación circunstancial. La función del juez es hallar una solución jurídica aplicando para ello los tipos o fórmulas legislativas, los cuales también están determinados, es decir, dados preexistentemente (principio de legalidad). Pero, desde el punto de vista de la decisión que el juez debe adoptar tanto el caso presente como las normas jurídicas aparecen como

42 Es «fácil» y está «al alcance de cualquiera» sentar que la generosidad es virtuosa: ahora, dar dinero a la persona adecuada, en la cantidad adecuada, en el momento oportuno, por la razón debida y de la manera apropiada «ya no todo el mundo puede hacerlo y no es fácil»; por ello, «es cosa trabajosa ser bueno» (Ét. Nic., II, 9,1109 a 23 y ss.).

${ }^{43}$ Cfr. Ét. Nic., V, 1, 1129b25-1130a13.

44 En el tema wittgensteiniano del rule-following esta cuestión se planteó como el problema de la relación interna entre una regla y sus aplicaciones (cfr. WITTGENSTEIN, 1999: $\$ \$ 201,202,217$ ), que desembocó (vía KRIPKE) en el callejón sin salida del escepticismo de las reglas. El problema queda resuelto reparando en que lo que se reputa «indeterminación» (la construcción aplicativa permite cualquier solución y hace indeterminada a la regla) es en realidad «incertidumbre» (la aplicación correcta existe pero no puede ser averiguada por adelantado) (DwORKIN, 2011: 91)

${ }^{45}$ Ret., I, 1, 1354b8, 3. 
indeterminados (esto es, inciertos): pues lo que debe deliberar el juez es justamente en qué concretos términos se ha de producir la calificación de los hechos del caso desde las normas o la relevancia de las normas con relación a los hechos, con vistas a determinar una respuesta jurídica (la condena o la absolución, la admisión o rechazo de la pretensión) ${ }^{46}$. Pues bien, aunque los criterios que la rigen son heterónomos y estén prefijados, y se trata de una deliberación retrospectiva y reglada, ésta exige un discurso práctico interpretativo autónomo, específico, que condiciona y hasta modifica el significado de la regla (la connotación de sus términos o predicados por el legislador) en relación con cada caso particular. La razón es que las situaciones prácticas a las que se aplican las normas jurídicas son siempre cambiantes e irrepetibles: cada caso es una singularidad y sólo mediante valoraciones ad hoc puede ser conformado a esas reglas de manera coherente.

De ahí la célebre aseveración de ARISTÓTELES: «Pues si el objeto es indeterminado [aoristou] también la regla es indeterminada, como sucede con la regla de plomo de los constructores lesbios: ésta no es rígida sino que se adapta a la forma de la piedra y así también los decretos particulares se adaptan a los casos [pragmata]» (Ét. Nic., V, 10, 1137a, 29-33). Es decir, las normas son las mismas, pero el modo como ellas son aplicadas en cada caso no puede ser el mismo si resulta que los casos son siempre distintos: si las combinaciones de propiedades que definen la connotación legal se dan necesariamente en proporciones diferentes en cada uno de los casos particulares que el juez tiene la obligación de denotar. El problema, por tanto, «no es imputable a la ley ni al legislador, sino a la naturaleza de las cosas prácticas [physei tou pragmatos], pues la materia práctica [praktēn bylē] está intrínsecamente conformada de esa manera» (1137a, 17-20). Se trata, pues, de la temporalidad y del carácter de segundo grado que posee la práctica de la legislación y la jurisdicción respecto de la práctica social primaria, la cual aparece como una suerte de «corriente heraclítea» en donde ninguna situación es idéntica a otra y por tanto ninguna regla mediante la cual pretenda ser anticipada y gobernada puede permanecer idéntica a sí misma. La pretensión de identidad (de sujeción a reglas generales), de continuidad de ciertos valores, exige necesariamente la variación y el cambio (la incesante adaptación de esas reglas) en la práctica de su aplicación. Ese es el precio de la coherencia.

La denotación judicial, la subsunción o calificación jurídica, no depende entonces centralmente de ningún procedimiento «lógico-lingüístico» de naturaleza algorítmica (en el sentido de una derivación de lo general a lo particular, de la inclusión «mecánica» del caso específico en el caso genérico), sino de un juicio evaluativo acerca de la corrección o incorrección en cada caso de dicha subsunción o clasificación de los hechos bajo la connotación de la regla o término legal de que se trate. ¿Desde qué criterio tiene lugar tal evaluación? Como hemos insistido, bajo el modelo práctico aristotélico tal criterio no puede ser otro que los valores o balances de valores que justifican la propia regla y en términos de los cuales se formulan los predicados fácticos de sus

46 Señala ARISTÓTELES respecto de la calificación e interpretación que «en cuanto no la ha definido el legislador, la ha de determinar el mismo juez y no aprenderla de los litigantes» (Ret., I, 1, 1354a30-1). Pero también, en lo que sí está determinado por el legislador (esto es, «lo verdadero», to alêthes [1354b10]) es responsabilidad del juez hacer que se imponga el criterio legal y no dejar que sea pervierta por el interés y la conveniencia de las partes. 
antecedentes y las consecuencias jurídicas correspondientes (esto es, la planificación de la coacción estatal en sentido amplio). Si esos valores se ven satisfechos, preservados o realizados en el caso en cuestión (que es, recordemos, la finalidad última perseguida por la legislación y la razón de ser de la propia jurisdicción) a la vista de las consecuencias prácticas que la aplicación de la regla supondría, entonces está justificada tal aplicación. Serían los llamados casos fáciles, aquellos en que tiene cabida una interpretación literal. Pero advirtamos que no es la lógica la que determina la «facilidad» de la solución de estos casos sino el juicio valorativo mediante el cual el aplicador estima que las razones subyacentes a la regla prevalecen en el caso particular y se preserva así la continuidad axiológica con los propósitos del legislador: es decir, la coherencia. Si, por el contrario, el valor que la regla pretende promover resulta frustrado o defraudado en el caso, entonces es preciso apartarse de la regla, romper su consistencia lógica y derrotarla, es decir, modificarla interpretativamente: es la equidad como corrección de la ley de la que nos habla ARISTÓTELES, que implica introducir excepciones a las reglas a la luz de los casos y, por tanto, apartarse de la interpretación literal.

\section{5.}

Observemos que aquí reside el punto decisivo que separa la equidad de FERRAJOLI y la equidad de ARISTÓTELES. Para ambos la equidad consiste en valoraciones. Pero para el primero, se trata únicamente de valorar las circunstancias singulares de cada caso (connotación), una vez asumido que caen bajo la regla (denotación). Mientras que para el segundo, es la evaluación de las circunstancias desde la regla la que determina si caen o no bajo la regla. En el primer caso tenemos un concepto logicista y formalista de las reglas jurídicas, cuya relación con los casos es exclusivamente lógico-semántica (en el fondo sintáctica, como vimos) y regida por el valor de verdad; en el segundo, tenemos un concepto pragmático de las reglas jurídicas, en el que esa relación se da por la mediación de los valores que las justifican.

Es crucial advertir que la oposición entre ambas no puede formularse - y esta es una falacia frecuentada por FERRAJOLI- como la que media entre una justicia formal basada en reglas y una justicia material de carácter decisionista o sustancialista, que (proporcionalmente a su defensa del objetivismo ético) sería proclive a desconsiderar el papel de las reglas y de la «racionalidad formal» ${ }^{47}$. La equidad aristotélica (y la comprensión pragmática de éstas que le subyace) no rechaza la «justicia formal» derivada del manejo de reglas (sino que la presupone): sólo rechaza una visión formalista de la misma. Este formalismo tiene que ver con el desconocimiento de los límites marcados por la dimensión justificativa de las reglas. La equidad aristotélica no niega la idea de generalidad que es consustancial a la idea de regla. Como vimos, ARISTÓTELES vincula la justicia política a la igualdad y esta (junto con la «sabiduría de los muchos» de la democracia) es la razón por la que las leyes tienen que ser universales (katholou). El uso de categorizaciones generales es una exigencia de la justicia: tratar lo igual de modo

4745 y ss., 216 y ss., 370 y ss.; FERRAJOLI, 2011a: I: 534 y ss.; II, 42 y ss. La falacia se refuerza notablemente al hacer figurar del lado, no ya del iusnaturalismo, sino de las concepciones penales autoritarias a las teorías del derecho que defienden el cognoscitivismo ético y la conexión derecho-moral. 
igual, dar la misma respuesta a los mismos casos. Pero esta justificación formal es sólo un derivado de la justificabilidad material, es decir de la recursividad del valor subyacente: esa «identidad» que está a la base de toda regla —aplicar al mismo tipo de casos la misma solución - no es en última instancia lógica, sino axiológica. El sentido formal de la justificabilidad de una decisión (la remisión a la generalidad de la formulación de la regla) es instrumental respecto de su sentido material o sustantivo. Esto es lo que expresa en realidad el principio de legalidad, entendido como principio político-moral. El fin de la consistencia lógica —en una empresa práctica- es la coherencia valorativa. Y por eso cuando aquélla frustre o comprometa ésta, es decir, cuando la generalidad de la regla sea un obstáculo para que los valores de justicia descuellen en un caso y se vea interrumpida la continuidad o coherencia axiológica, la «identidad de valor», con el legislador ${ }^{48}$, entonces debe ser corregida: la justicia exige en tal situación tratar lo desigual de forma desigual y lo injustificado — lo «formalista»— es mantener la regla igual para casos relevantemente distintos, sacrificar la coherencia por la consistencia. Por eso dice ARISTÓTELES que la equidad es la «justicia que va más allá de la formulación de la regla [to para ton gegrammenon nomon dikaion]», que corrige «el error que resulta de su carácter universal» (1137b, 24-27). Esa dimensión valorativa es precisamente lo que hace de la equidad un tipo de justicia «mejor» (beltion) y «superior» (kreitton) respecto de la justicia legal (nomikon dikaion), pero ello no supone que deje de ser universalizable y de plasmarse a su vez en reglas prácticas, lejos de toda justicia sustancial de carácter «particularista» (ZAHND, 1996: 290).

En esta concepción pragmática de las reglas, el razonamiento práctico del juez puede quedar desvinculado de la formulación literal de las reglas del legislador, pero no desvinculado de la coherencia axiológica con el razonamiento práctico del legislador, a través del caso y la regla concernida. Sólo esto permite presentar a las excepciones como distintas de meras contravenciones de las reglas, esto es, como justificadas, a diferencia de lo que sucede cuando el razonamiento se ve como simple subsunción o consistencia lógica con las reglas legislativas. Por eso señala ARISTÓTELES que la razón de la corrección equitativa es que «el propio legislador» habría corregido la regla «si estuviera presente y hubiera conocido el caso» $(1137 b, 23-24)$. La corrección de la regla (epanorthoma nomou) va orientada, pues, a la construcción de la regla correcta u orthos logos (no a desligar al juez de toda regla, como si fuera un árbitro o cadí) ${ }^{49} \mathrm{y}$ supone que la interpretación tiene un carácter contrafáctico, ideal, precisamente en tanto envuelve una justificación que va más allá del «legislador histórico» para hacer relevantes los valores que comunican su decisión (la regla) con la decisión presente $(\text { el caso })^{50}$.

En consecuencia, la continuidad pragmática y de fines que de acuerdo con este modelo se produce entre legislación y jurisdicción debe entenderse como continuidad

48 Eso es lo que sucede con los supuestos que SCHAUER (2002) llama «recalcitrantes» de supra- e infrainclusión, en donde la generalización de la regla contradice en el caso su justificación subyacente, es decir, el valor que le dota de sentido práctico. En realidad, no son sino los supuestos reconocidos en la tradición jurídica de desajuste entre la letra de la ley y la intención del legislador (plus dixit quam voluit y minus dixit quam voluit).

49 «Pues un árbitro se rige por la equidad del caso, mientras que un juez se rige por la ley» (Ret., I, 13, 1374b23).

${ }_{50}$ Esta reconstrucción valorativa de carácter retrospectivo es lo que a veces se ha llamado, en la metodología jurídica, la «interpretación teleológica objetiva». 
de los valores sustantivos de carácter político-moral, no de los valores formales o institucionales, que serían meramente instrumentales respecto de los primeros. Sólo en la perspectiva «arquitectónica» de la constitución y la legislación como normas expresivas de valores sustantivos que expresan una cierta concepción político-moral de la justicia y que pretenden ser puestos en práctica de modo recurrente por la intermediación de una pluralidad indefinida de aplicadores en una colección indefinida de situaciones futuras pueden hallar sentido propio los valores formales e institucionales que van instrumentalmente asociados a ellos (la igualdad ante la ley, la igualdad en la aplicación de la ley, el principio de legalidad, el de seguridad jurídica). El diseño político del Estado de derecho, por tanto, no puede significar que estos valores formales operen exclusivamente como límites o restricciones a las valoraciones sustantivas de los jueces (valoraciones que per se deberían ser desterradas del ejercicio de la jurisdicción por ser ajenas a su racionalidad «cognoscitiva») y que sean los valores sustantivos los que deben entenderse como instrumentales. Por el contrario, presupone que el principio de jurisdiccionalidad es solidario de un ideal metódico de coherencia que requiere el desarrollo autónomo de una jurisprudencia cuya función primaria es valorar y deliberar en última instancia en términos de justicia material a partir de las leyes a fin de determinar su aplicación correcta y justificada (orthos logos) caso a caso, que es aquella que conduce a propagar efectivamente en la práctica los valores que la legislación pretende alcanzar ${ }^{51}$. Aquí habría una suerte de «asimetría justificativa» básica (cuyo desconocimiento es seña característica de todo formalismo jurídico) que determina que de los valores formales e institucionales del derecho (que justifican su consistencia al nivel de sus reglas) no pueden derivarse los valores materiales o sustantivos (las justificaciones últimas), mientras que eso sí sucede a la inversa.

Lo anterior es tanto como reconocer el carácter necesariamente dinámico y no estático, creativo y no pasivo, de la jurisdicción: ni las respuestas correctas ni las excepciones o correcciones precisas son en rigor anticipables por el legislador, sino que tienen que ser construidas caso a caso por el juez considerando y evaluando las diferencias relevantes que las situaciones particulares van presentando, lo que sucede tanto en un sistema de legislación como en uno de elaboración judicial de precedentes (basado en la técnica del distinguishing). La tesis aristotélica de la equidad sienta así las bases de la interpretación jurídica como la labor constructiva y racional-deliberativa (prudencial) consistente en reconocer y confirmar pero también ampliar y restringir el alcance de las reglas legislativas como parte de la práctica de su aplicación. Se adelanta a la tesis central de la hermenéutica según la cual la interpretación modifica necesariamente el sentido de lo interpretado al entenderlo mejor de lo que su autor pudo entenderlo. Los criterios de la equidad son en realidad los cánones constructivos de la interpretación jurídica: «Mirar no a la ley, sino al legislador; no a la letra, sino a la intención [dianoian] del legislador; no al hecho, sino a la intención; no a la parte, sino al todo; no cómo es ahora el acusado, sino cómo era siempre o la mayoría de las veces» (Ret., I, 13, 1374b, 11). Se adelanta igualmente al ideal metódico de la única respuesta correcta, es decir de la mejor respuesta posible, como criterio rector de la

51 Como señala AmAYA (2012: 88), el ideal de coherencia «se basa en una concepción amplia de la racionalidad práctica según la cual el razonamiento jurídico no es un razonamiento exclusivamente instrumental sino que, por el contrario, es también un razonamiento acerca de fines y valores». 
práctica de la jurisdicción ${ }^{52}$, puesto que la equidad es en efecto una «mejor» forma de justicia dada en el contexto de la justicia legal (una perfección respecto de la virtud que ésta ya es en cuanto práctica de aplicación de reglas) precisamente por constituir su anclaje axiológico y por tanto su fundamentación última. Resulta evidente que la idea de una «mejor respuesta» sólo tiene cabida en el escenario deliberativo de una dialéctica entre concepciones del valor alternativas, lo que da por descontado que los desacuerdos sustantivos son desacuerdos efectivamente axiológicos que se desencadenan a la hora de reconstruir los materiales jurídicos y la práctica pretérita desde teorías político-morales rivales a la hora de integrar, como señala DwORKIN, tanto el ajuste formal con los mismos ( $f t$ ) como su justificación de fondo (soundness). Esas teorías o concepciones son «interpretativas» porque coinciden en reconocer que el derecho es «la mejor justificación de nuestras prácticas jurídicas» (DwORKIN, 1986: vii) al tiempo que difieren en cómo deben ser entendidos los valores involucrados en un cierto momento o situación de la práctica (presuponiendo con ello que deben serlo de algún modo más correcto que otros). De nuevo, el desacuerdo no abona el escepticismo o el no cognoscitivismo valorativo (la indeterminación radical) sino sólo la incertidumbre a la hora de construir cada decisión en una empresa práctica en curso cuyos criterios rectores son valores asumidos como objetivos.

Por supuesto, la tesis de la equidad presupone asimismo por todo ello la distinción, dentro de las normas jurídicas, entre principios y reglas. Los principios son proposiciones prácticas máximamente abstractas precisamente en la medida en que expresan un horizonte ideal de valor a lograr o «maximizar», y esta dimensión axiológica los distingue de las reglas, cuya referencia «cerrada» a cursos de acción y fines les confiere una contextura inmediatamente práctica (directiva o teleológica). Es así como los principios tienen un carácter básico, orientador y fundamentador de la práctica jurídica en su conjunto, pero también de cada una de sus decisiones singulares. Si la deliberación legislativa supone la confección de reglas desde la adopción de una tabla de principios implícitos o expresos, la aplicación de aquéllas resulta imposible al margen de éstos como rationes decidendi subyacentes a sus formulaciones. La interpretación judicial (ante lagunas y antinomias) se produce necesariamente a base de razonamientos de principio (en términos de analogía, identificación de «ilícitos atípicos», etc.), lo que significa que en ellos afloran consideraciones valorativas - no sólo lógicas- en las que entran en juego ponderaciones electivas tanto al establecer las excepciones o inaplicaciones in casu de las reglas como al formular nuevas reglas. La «derrotabilidad» de las reglas no es por tanto una propiedad derivada de su estructura lógica sino de su estructura justificativa ( $c f r$. RÓDENAS, 2012: 31 y ss.). Esto corrobora otra vez, por lo demás, que la equidad no es ningún expediente particularista, ya que convierte al caso excepcionado en regla para casos similares en el futuro o supone la creación de nuevas reglas. La proximidad de este planteamiento metodológico de la práctica de la jurisdicción con el diseño del Estado constitucional, que se caracteriza por la institucionalización, mediante una constitución normativa rígida, de determinados valores en forma de principios, resulta patente desde el momento en que dicho diseño - como requerimiento de su coherencia, es decir, de la garantía de tales valores en la prácticadebe institucionalizar también la corrección de las reglas legislativas mediante el control

52 Sobre la «inferencia a la mejor explicación en el derecho», cfr. AMAYA, 2012: 76 y ss. 
judicial de constitucionalidad. Ahora no se corrigen solamente las reglas legislativas en términos de excepciones sino que la propia autoridad del legislador, sus propias valoraciones político-morales (es decir, no los «errores de la ley» sino los «errores del legislador») $)^{53}$ es fiscalizada a la luz del sistema de principios y valores constitucionales en su integridad, lo que compromete a los tribunales constitucionales a articular interpretaciones comprensivas de calado necesariamente político y moral y, por ello, de alcance filosófico (DWORKIN, 2010).

\section{6.}

Si volvemos a FERRAJOLI, para concluir con esta comparación crítica, resultará innecesario decir que desde su planteamiento positivista una concepción pragmática de la función judicial tan abiertamente comprometida con la prioridad metódica del valor (de la justicia) como la que supone la equidad aristotélica no podría conducir más que a «funestas» consecuencias, en el exacto sentido de FILANGIERI. Es decir, equivaldría a la definitiva consagración metodológica de la arbitrariedad, la discrecionalidad, el decisionismo y el activismo judicial. En sus propias palabras: a dejar «el espacio abierto a los sofismas y sofisterías, que podemos definir, en oposición a la [verdadera] equidad, como el arte de acreditar identidades donde hay diferencias esenciales y diferencias donde hay identidades, gracias a la posibilidad de extender o de restringir a placer los confines indeterminados de la denotación legal» (162, añadido mío). Desde el punto de vista de la concepción general del derecho, significaría abrazar definitivamente la confusión de los límites del derecho con la moral, el absolutismo, el sustancialismo, la subversión del Estado de derecho al debilitar la normatividad de la ley o la constitución y convertir a los jueces «en legisladores», etc. (FERRAJOLI, 2011b: 44; 2012: 816-817).

Sin embargo, como he intentado mostrar en las páginas anteriores, este conjunto de ideas - que forman un tópico aún muy asentado, como resultado de la influencia de la cultura jurídica positivista contemporánea- son solidarias de una epistemología fundamentalmente errónea basada en la dicotomía hecho-valor que establece una fractura injustificada dentro de la jurisdicción entre los valores de verdad, por un lado, y los valores político-morales, por otro, e invierte las verdaderas relaciones entre ambos. Asumiendo que los juicios de valor prácticos son irracionales o a-racionales, la genuina pretensión metódica de esta concepción es excluirlos del núcleo del razonamiento judicial para hacer de la verdad su valor dominante, bajo el supuesto epistemológico de que la racionalidad jurídica (la dada en la conexión legislaciónjurisdicción), si es tal, debe responder a una racionalidad teórica (científica, tendencialmente), incluso tras conceder que lo que con ese valor se trata de asegurar no son sino valores prácticos de carácter político-moral. Tanto en el caso de que esa pretensión posea rango teórico (que su fin sea describir los ideales del Estado de derecho moderno de raíz liberal) como si es de orden normativo (que persiga promover -mediante la teoría - esos ideales) resulta epistemológicamente inconsistente, y esta inconsistencia queda patentizada, en el caso de FERRAJOLI, en el sesgo que imprime al concepto de equidad.

53 Cfr. sobre esta distinción SCHAUER, 2002: 154. 
En efecto, en su esquema la equidad del juez queda reducida a una «comprensión» del caso que forma parte también de la dimensión cognoscitiva del juicio yuxtapuesta a la verificación. FERRAJOLI intenta en primer lugar presentarla como nada más que un «conocimiento» de lo particular de cada caso (más bien que una «valoración»). Pero, en esa medida, se ve ya imposibilitado de ligar dicho «conocimiento» a una idea estricta de verdad (científica), como sucede con el poder de comprobación fáctica: es una «comprensión» que remite justamente al tipo de conocimiento interpretativo ligado a valores que la tradición hermenéutica asoció distintivamente a las ciencias sociales frente a las naturales (el Verstehen de DiLTHEY y WEBER). También recuerda inevitablemente a la propia idea de phronēsis (ella misma tan emparentada históricamente con el Verstehen), y así cita FERRAJOLI — ahora laudatoriamente- a ARISTÓTELES a propósito de la prudencia como virtud del «discernimiento» (201-202) ${ }^{54}$. Pero FERRAJOLI malentiende la idea aristotélica pro domo sua, pues - como vimos- para el Estagirita la prudencia no consiste meramente - como ciertas interpretaciones han vulgarizado- en la comprensión de los elementos particulares de cada caso, sino en la evaluación de los mismos en tanto deben ser encajados en una norma - que es la que suministra los criterios de relevancia o propiedades genéricas que permiten la identificación e individualización en el juicio de tales elementos particulares-, norma cuya adecuación o correcta aplicabilidad depende justamente del modo en que dicho encaje sea coherentemente resuelto por el juzgador a la luz de los valores subyacentes a esa norma. De modo que la prudencia es ciertamente relativa al caso particular, pero incluye al mismo tiempo una consideración de carácter universal. Y no sólo porque sea también relativa a un estándar normativo general: sino sobre todo porque es ella misma normativa ${ }^{55}$. Es decir, aplicar una norma envuelve un razonamiento práctico cuya conclusión no es simplemente una proposición sino en realidad el arranque de un curso de acción avalado por ella como correcto no exclusivamente en relación con este caso sino justificado para todos los casos similares ${ }^{56}$. La prudencia, por lo tanto, no puede consistir solamente en una comprensión cognoscitiva particularista «de hechos» sino que es indisociable de la operación de calificación o denotación jurídica de

54 «El llamado juicio [gnomê], en virtud del cual decimos de alguien que tiene buen juicio y que es comprensivo, es el discernimiento recto [krisis orthê] de lo equitativo. Señal de ello es que llamamos comprensivo, sobre todo, a lo equitativo, y equitativo a tener comprensión sobre algunas cosas, y juicio comprensivo al que discierne rectamente lo equitativo, y rectamente quiere decir de acuerdo con la verdad» (Ét. Nic., VII, 11, 1143a19-24; FERRAJOLI omite esta última frase, acaso porque ARISTÓTELES se está refiriendo a la verdad por la que se define la prudencia, es decir, la verdad como corrección práctica y no la verdad como comprobación fáctica).

55 «En efecto, la prudencia es normativa: qué se debe hacer o no, tal es el fin que se propone» (Ét. Nic., VI, 10, 1143a8).

56 Eso es lo que quiere decir que la virtud consiste en una «disposición» o «hábito» o «modo de ser» (hexis): su objeto es generar prácticas recurrentes justificadas (o sea, ser «generosos», «justos», etc., generalmente, pues «una golondrina no hace verano»: «los hombres se hacen justos practicando actos justos» $\mathrm{y}$ «sin practicarlos nadie podría siquiera esperar convertirse en bueno», Et. Nic., II, 4, 1105b9-12), por más que sólo la prudencia pueda determinar qué conducta es correcta en cada situación particular. La justicia es, como sabemos, virtud de segundo orden: los hábitos de que trata (aquellos que el legislador persigue introducir en la práctica social) presuponen ya hábitos establecidos de primer orden. Y así como la virtud moral es el balance correctivo entre dos vicios, la virtud de la justicia se logra en la corrección de las desviaciones de primer grado - los ilícitos (justicia correctiva) y las desigualdades (justicia distributiva) — por medio de la práctica de aplicación judicial de las leyes. El elemento de valor (la virtud moral del ciudadano, la justicia del juez) emerge así en la «trayectoria» recurrente descrita por los cursos de acción virtuosos respectivos (frente a las que encarnan sus contravalores: los vicios y las injusticias, sean éstas ilícitos o desigualdades). 
los mismos y, por tanto, constituye una operación evaluativa, crítica, que significa la modificación e incluso corrección de la regla (en términos de un orthos logos justificado y universalizable). Es este «reverso» epistemológico de la idea axiológica de virtud el que, como hemos visto, se torna expreso en la doctrina aristotélica de la equidad en relación con el razonamiento judicial. Incluso en su dimensión denotativa o subsuntiva (verdad jurídica), el razonamiento del juez es práctico debido a su contextura esencialmente valorativa, que lo hace irreductible a un razonamiento teórico precisamente porque -en su ensamblaje con el legislativo, cuyo resultado es una proposición universal pero de fundamento exclusivamente axiológico- está destinado a reproducirse en una multiplicidad de casos particulares y, por ello, a ser justificado individualizadamente en cada uno de ellos en términos de coherencia. De ahí la tesis aristotélica de que en materia moral o jurídica lo correcto, lo justo —el valor en suma- no puede ser establecido en general, sino sólo en el ajuste con los particulares, o sea, en la práctica ${ }^{57}$. Es la prudencia la que salvaguarda este ajuste coherente y la que, por tanto, produce el valor: su dirección de ajuste es «lenguaje-a-mundo» y representa al sujeto como agente en primera persona, como sujeto de un razonamiento práctico (sometido por ello a potencial elogio o censura en cuanto a su corrección bajo el punto de vista de esos valores y su efectiva realización o falta de ella en la práctica). Vale la pena recordar aquí que el intento de convertir la prudencia y la equidad en operaciones «teóricas», distanciadas de la práctica, ya fue emprendido por algunas interpretaciones escolásticas del aristotelismo que pretendieron construir una ethica non includens prudentiam, es decir, una ciencia moral consistente solamente en normas y principios universales y objetivos, independientes de su proceso de aplicación. Esta última quedaría reducida simplemente a comprensión de los particulares del caso para su subsunción lógica bajo la norma universal ( $c f r$. NussBaum, 1985: 167 y ss.). Un tal modelo de racionalidad práctica (que por esa misma vía llegaría a la teoría del silogismo perfecto de los ilustrados) es el que acaba abrazando paradójicamente FERRAJOLI: el modelo de una iurisprudentia non includens prudentiam.

La contradicción insuperable que supone una iurisdictio que no es iurisprudentia, una jurisdicción que segrega del juicio la prudencia bajo la apelación a la verdad (es decir, a la lógica), se agudiza dramáticamente al menor análisis crítico, revelando inconsistencias cuyo alcance afecta al conjunto de la concepción del derecho subyacente. Para empezar, como ya sabemos, FERRAJOLI ha debido pasar a reconocer que la connotación - la equidad- consiste esencialmente en juicios de valor (no es sólo un «conocimiento de lo particular del caso», de los «hechos»), con lo cual se desmiente que forme parte de la cognición judicial y se vincula a la «discrecionalidad» del juez ${ }^{58}$. Una discrecionalidad que, se añade, es insuprimible y - a diferencia del poder de

57 «Pues cuando se trata de enunciados sobre acciones, aquellos que son universales (katholou) tienen una aplicación más amplia (koinoteroi), pero los particulares son más cercanos a la verdad, porque las acciones son relativas a situaciones particulares, y es con éstas con las que hay que estar de acuerdo». «Tampoco la prudencia se refiere solamente a lo universal: tiene que reconocer también lo particular, pues es práctica y la práctica tiene que ver con lo particular» (Eth. Nic., II, 6, 1107a29-32; VI, 7, 1141b15-17. Cfr. también II, 2, $1104 a 5$ y ss.)

58 «Cuando un juez toma conocimiento de un delito, aunque esté denotado por la ley de forma taxativa, no se limita a aseverar (o a negar) conforme a pruebas (a no pruebas o contrapruebas) la tesis que enuncia su comisión por parte de un sujeto culpable. Valora también, a los fines de la decisión sobre la medida y/o sobre la calidad de la pena, la gravedad específica del hecho en relación con el contexto ambiental en que se ha veri- 
disposición - legítima («fisiológica») siempre y cuando no afecte a la denotación (a la verdad jurídica). Esto es: siempre y cuando el juicio de valor no afecte a la norma jurídica, sino sólo a los hechos del caso. «La valoración equitativa no se refiere nunca, en realidad, al caso abstracto, sino siempre al caso concreto y humanamente determinado» (164). Ahora bien, FERRAJOLI afirma a continuación que esta valoración equitativa manifiesta no sólo la sensibilidad y la inteligencia sino «la moralidad del juez» (id.). La tesis ferrajoliana de la equidad se hace equivalente así a la tesis de la separación derecho-moral. Los juicios de valor en cuestión se manifiestan ahora, en efecto, como juicios morales. Y este es el verdadero quid de todo el asunto, porque sabemos que si la denotación judicial ha de ser valorativa (es decir, connotativa) es porque entronca con la propia connotación de la ley y consiste en hacer congruentes la valoración del caso concreto con la valoración del caso genérico, a través de un juicio (deferido) en primera persona. Reconocida nolens volens la necesaria presencia de la moralidad del juez en la aplicación del derecho, FERRAJOLI trata de debilitar el nexo institucional que la conecta con la figura político-moral del legislador. Para ello, presenta esta moralidad como puramente subjetiva, en el sentido de que envolvería las valoraciones del juez como individuo pero no como juez. Paradójicamente, FERRAJOLI convierte así a la equidad en una suerte de aequitas cerebrina ${ }^{59}$. La equidad sería una comprensión «simpatética», que entraña la indulgencia ${ }^{60}$, la pietas, el perdón (tout comprendre est tout pardonner), virtudes todas ellas que acercan a la persona del juez al caso (al sujeto juzgado, al delincuente como individuo) (165, 202-203). Pero, en cuanto tal juez, por el contrario, la dimensión esencialmente cognoscitiva y veritativa del juicio le distancia moralmente del caso, le lleva a la neutralidad valorativa, a la indiferencia axiológica, a la imparcialidad. Pensemos, sin embargo, que esta manera de presentar las cosas apelando a la neutralidad moral del juez — tan plausible a primera vista - resulta objetable si tenemos en cuenta que ese distanciamiento se produce también al entender la connotación como determinante de la denotación (es decir, de la calificación e interpretación normativas) por más que hablemos de valoraciones del juez de naturaleza sustantiva político-moral: basta con darse cuenta de que los juicios de valor diferidos del juez presuponen que los actos que está juzgando son interpretados como disvalores que se trata de rectificar desde las normas legislativas. La distancia (y la imparcialidad), por lo tanto, se establece en realidad desde el compromiso con valores (con unos - los encarnados por la legislación - frente a otros), valores que - a través de las normas- son los auténticos sustentos de la justificación argumentativa, y no desde una pretendida indiferencia axiológica frente a los hechos y frente a las normas. La disociación entre la moralidad subjetiva del juez y la moralidad representada y ejercida por su función institucional tendría entonces un sentido totalmente diferente (que el adagio «odiar el delito y compadecer al delincuente» puede servir para ilustrar). Las virtudes judiciales en cuestión dejan de ser puramente subjetivas para pasar a tener una dimensión plenamente jurídico-institucional: pues a través de ellas como se establece

ficado, con sus causas objetivas y sus motivos subjetivos, con la intensidad de la culpabilidad, en una palabra, con las circunstancias específicas en las que el culpable ha actuado» (155-156).

59 En la tradición canónica se distinguía entre aequitas scripta, non scripta (o correctiva) y cerebrina; esta última era la que ex proprio capite indicis desumitur, o sea, la que proviene de valoraciones puramente subjetivas del juez, de su simple arbitrio.

60 «Ser indulgente con las cosas humanas es también de equidad» (Ét. Nic., I, 13,1374b11). 
la conexión interna justificativa entre derecho y moral, aquella que se da al nivel de los valores y los principios.

¿De qué otro modo si no podría FERRAJOLI establecer la estrecha asociación que postula entre la connotación - la equidad - en derecho penal y el favor rei como su fundamental principio inspirador, del cual depende nada menos que todo su sistema garantista de derecho penal mínimo? El favor rei actuaría a través de la aplicación de las atenuantes genéricas y eximentes de la responsabilidad penal y significaría por tanto la exclusión del delito en función de juicios de valor sobre la gravedad del caso particular (165-166), lo que demuestra que la equidad sí es un juicio que necesariamente afecta a la denotación (al caso genérico y no sólo al caso particular) y que lo hace precisamente a la luz de los valores subyacentes a las reglas (la antijuridicidad). Por cierto que precisamente el único ejemplo que ARISTÓTELES nos ofrece del razonamiento por equidad es justamente un ejemplo penal de esta índole ${ }^{61}$. El principio favor rei está vinculado, dice FERRAJOLI, al principio de dignidad humana: difícilmente puede considerarse fundado, entonces, en la moralidad «puramente subjetiva» del juez. El arte de acreditar diferencias esenciales donde hay identidades e identidades donde hay diferencias, a la hora de determinar el alcance de la denotación legal resulta ser, en suma, algo más que pura «sofistería»: es la clave de la racionalidad (o irracionalidad) del derecho penal. No cabe despacharla diciendo que «el juez, en un sistema de legalidad, connota de manera distinta lo que la ley denota, y denota de manera igual lo que la ley connota». Lo que dice ARISTÓTELES es que - precisamente porque no puede prever denotativamente todos los casos posibles de la práctica - la ley siempre es una connotación además de una denotación (el legislador razona desde valores presupuestos) y el razonamiento del juez no podrá ser solamente una denotación, ni una denotación igual en todos los casos, precisamente por incluir una connotación. La determinación de lo que aquí es «idéntico» y lo que es «distinto», dado que los juicios de relevancia son axiológicos, está estrictamente en función de razonamientos que comprometen al juzgador en términos coherentistas con aquellos valores, y tal compromiso no es sino la forma en que acaece la conexión justificativa entre el derecho, la moral y la política.

Y si, por último, consideramos el elemento final del modelo ferrajoliano de jurisdicción, el poder de disposición, podremos comprobar que el reconocimiento malgré lui de la centralidad que los juicios de valor tienen en el razonamiento judicial termina por convertirse en un auténtico caballo de Troya que autodestruye definitivamente la concepción cognoscitiva del juicio. Ese poder, recordemos, consiste según FERRAJOLI exclusivamente en juicios de valor distintos de la verdad, es un poder puramente

${ }_{61}$ «En efecto, la equidad parece que es justa, pero es un tipo de justicia que va más allá de la ley escrita. Ello sucede unas veces por propia intención del legislador y otras veces por inadvertencia suya. Sucede intencionalmente cuando el legislador no puede tipificar o definir las acciones con precisión y, sin embargo, es necesario que se pronuncie en términos universales, remitiéndose en su ley así solamente a lo que sucede con mayor frecuencia. En muchos casos la práctica no es fácil de definir a causa de su indeterminación. Por ejemplo: ¿cuántas clases de armas y de qué tamaño deben considerarse para definir el delito de herir a otro? Toda una vida no sería tiempo bastante para enumerar todas las posibilidades. Por tanto, si las acciones son imposibles de definir con total precisión y, sin embargo, es necesario establecer una ley, ésta no tiene más remedio que hablar en términos generales. Y así, en el mismo ejemplo, alguien que llevara un anillo y, al levantar su mano, golpeara a otro, habría cometido el delito de herir con arma desde el punto de vista de la literalidad de la ley, siendo así que, desde el punto de vista de la equidad, no es en realidad culpable de tal delito» (Ret., I, 13, 1374a27-1374b1, traducción mía). 
«pragmático», o sea, valorativo ${ }^{62}$ : en él reaparece la figura ético-política del juez que hasta el momento quedaba oculta, «contenida», en la reconstrucción del juicio, ya que como vimos era considerado un poder «estructuralmente ilegítimo», «patológico», que todos los demás poderes tenían por misión reducir o neutralizar. El poder de disposición del juez consiste en la autonomía del juez para «integrar después del hecho el supuesto legal con valoraciones ético-políticas de naturaleza discrecional» (171). Esas valoraciones ético-políticas son extra- o metajurídicas, responden a valores sustanciales respecto de los que en el Estado de derecho sólo corresponde legítimamente pronunciarse al legislador (172) y que, en consecuencia, en la instancia judicial deben ser restringidas por los valores de verdad, siendo su ilegitimidad proporcional a la disminución de la certeza semántica del derecho (o al incremento de sus «intersticios»: HART, 1994: 275). Ya hemos enfatizado la incoherencia radical que supone considerar «ilegítimo» precisamente a aquel poder sobre el cual descansa la racionalidad de la aplicación judicial del derecho en su integridad. Importa ahora subrayar, en particular, cómo FERRAJOLI vincula el poder de disposición al «deber de decidir» del juez, a la «responsabilidad de las decisiones» (que remonta al art. 4 del Code Napoléon, que establece la prohibición del juicio de non liquet) y, por tanto, al deber de justificar la decisión. Sabemos que entender este «deber» como «jurídico» no es más que el modo positivista de hacer descansar sobre la práctica de la jurisdicción la realización y cumplimiento social de los valores político-morales que la legislatura le encomienda, en el esquema del Estado de derecho, como «institución de garantía». Resulta muy significativo cómo, pese a referirse FERRAJOLI aquí al deber de decidir en ausencia de determinación legislativa (de denotación verificable) o en presencia de indeterminación, y por tanto a una decisión construida «sólo o predominantemente mediante juicios de valor», tal decisión adoptada tan sólo en virtud de tomas de posición ético-políticas resulta tornarse repentinamente en «racional»: pues, nos dice ahora el autor italiano, «también los juicios de valor son susceptibles de argumentación y de control conforme a criterios pragmáticos de aceptación» (173). ¿Cuáles serían esos criterios pragmáticos de aceptación? La respuesta de FERRAJOLI no deja de resultar sorprendente después de todo lo dicho: los principios. En efecto, el poder de disposición del juez, ajeno a la verdad de la ley, debe proceder argumentando desde los principios constitucionales y los principios generales del derecho, sean explícitos o implícitos de elaboración doctrinal (id.). En aquello que no esté determinado por reglas legislativas — viene a decirnos FERRAJOLI- el juez debe regir su decisión por principios (o sea, «como si fuese un legislador»). Es, pues, la fórmula clásica heredada de la equidad aristotélica.

En suma, tenemos así que lo que FERRAJOLI llama «poder de disposición» encierra en realidad la sustancia de lo que ARISTÓTELES llama «práctica», y la «argumentación según criterios pragmáticos de aceptación» no es sino la phronēsis o prudencia aristotélica, esto es, la justificación crítica de la acción conforme a valores. Esta clase de racionalidad valorativa, lejos de hallarse confinada en ese poder «ilegítimo» supuestamente sólo residual o «intersticial», dejado abierto por la indeterminación de las reglas legislativas, ha de reconocerse activamente presente ya en los otros tres poderes que según

62 «Su ejercicio no supone motivaciones cognoscitivas, sino sólo opciones y/o juicios de valor de los que no es posible ninguna caracterización semántica, sino sólo caracterizaciones pragmáticas ligadas a la obligación de la decisión» (167). 
FERRAJOLI conforman la práctica de la jurisdicción: la denotación, la comprobación y la connotación. Eso es lo que se sigue de la tesis aristotélica de la equidad en relación con la racionalidad de la jurisdicción: la aplicación de las reglas jurídicas resulta imposible al margen de la referencia a sus valores o principios subyacentes, por cuanto de ello depende su correcta justificabilidad y, en definitiva, el cumplimiento del propio fin de la institución jurisdiccional. Y resulta muy difícil no considerar extensible esta conclusión al propio modelo de FERRAJOLI si consideramos los principios de los que éste nos habla: no sólo el favor rei y su corolario in dubio pro reo que rigen el poder de connotación - pero, como también vimos, el poder de verificación (al resolver las incertidumbres de la comprobación y los defectos de la denotación en favor del reo)sino también el principio de coherencia con los precedentes que rige la «paridad de tratamiento en casos (relativamente) iguales»y, en fin, los principios de «igualdad»y «libertad» (173). Como se ve, estos principios son nada menos que los fundamentos tanto formales (certeza, coherencia, igualdad) como sustantivos (libertad, dignidad, igualdad real) de un sistema jurídico en cuanto sistema de reglas prácticas. Si tales principios son el foco de proyección de los valores que justifican el propio derecho en su conjunto como institución normativa, fundar la jurisdicción en un «cognoscitivismo» de las reglas y de los hechos pero no de los valores resulta no ya reduccionista (formalista) sino indefectiblemente autorrefutatorio. La propia legitimidad del legislador — de la que se hace depender la del juez— no puede ser establecida más que en términos político-morales (sea a base de razones sustantivas últimas: la autonomía individual, o institucionales: la división de poderes en una democracia) ${ }^{63} \mathrm{y}$, por consiguiente, presuponiendo una objetividad mínima del valor. Las inconsistencias del constitucionalismo garantista de FERRAJOLI arrancan justamente de la pretensión de definir en exclusiva este valor por referencia a la autoridad (invirtiendo la asimetría justificativa de la que antes hablábamos), asumiendo que los principios se comportan como «reglas» rígidas cuya aplicación excluye toda toma de posición o juicio de valor porque consiste fundamentalmente en una subsunción ${ }^{64}$, porque responde a jerarquizaciones autoritativas previas o «soluciones en abstracto» ${ }^{65} \mathrm{o}$, en fin, porque la ponderación judicial no es en realidad de normas y valores sino de hechos ${ }^{66}$. En suma, arrancan de hacer residir la única garantía de legitimidad de los jueces en su papel «cognoscitivo», de aplicación de normas, y de considerar la producción de normas por su parte como «la degeneración del poder judicial» ${ }^{67}$.

63 Cfr. LAPORTA, 2009; SCHAUer, 2002. Ya ambas clases de consideraciones están perfectamente presentes, por cierto, en la filosofía política de ARISTÓTELES, para la cual el bien común es el «de todos y cada uno de los ciudadanos» y va conceptualmente ligado a la democracia como régimen de máxima libertad e igualdad y basado en la «sabiduría de los muchos».

64 Ferrajoli, 2011b: 34 y ss.; 2012: 802 y ss. Cfr. FerRajOli, 2011a: I, 684 y ss.

65 FERRAJOLI, 2011a: I, 711 y ss.; II, 70 y ss.; 2011b: 35 y ss.; 2012: 808 y ss.; 2013: $\mathbb{} 3$.

66 «Pero estos casos difíciles, resueltos por la ponderación, inevitablemente ligada a la valoración de sus circunstancias específicas, no son más difíciles que los ya mencionados del concurso de circunstancias agravantes y atenuantes del delito, o del límite (proporcionalidad a la ofensa o al peligro) al límite (legítima defensa o estado de necesidad), representado por las causas eximentes del delito. También en estos casos la ponderación se refiere, no tanto a los principios, como a las circunstancias de hecho que justifican su aplicación o su no aplicación» (FERRAJOLI, 2011b: 49). «Lo que se da aquí es una confusión entre hechos y normas. En efecto, pues en concreto lo que cambia no son las normas, siempre iguales, sino los casos juzgados, que, aunque subsumibles en las mismas normas, son siempre irrepetiblemente diversos unos de otros» (FERRAJOLI, 2012: 810).

67 FerRajoli, 2011b: 51, n. 91. 
Ahora bien, es evidente que si la diferenciación entre principios y reglas planteada por la constitucionalización de los sistemas jurídicos posee un carácter «estructural», es precisamente en la medida en que tenga que ver con el diferente modo como en ambos tipos de normas figuran los valores ${ }^{68} \mathrm{y}$, por tanto, con el diferente papel que hacen jugar a los juicios de valor en el razonamiento práctico, en la jurisdicción. Se trata, en efecto, bien de valorar en qué medida el curso de acción prescrito por una regla es el correcto en cada situación práctica a la luz de los principios relevantes, bien de seleccionar cursos de acción que sirvan a la realización de valores mediante su especificación en reglas concretas que, si es necesario, establezcan balances entre ellos. FERRAJOLI acepta que tras las reglas actúan los principios como sus fundamentos ${ }^{69}$, si bien son «opacas» en relación con éstos, y también que los principios son normas que «enuncian expresamente y, por ello, solemnemente, los valores ético-políticos que proclaman» (2011: 39). Pero entonces, en relación con lo primero, la jurisdicción sólo puede desempeñarse como una labor racional si tiene la capacidad para eludir los errores que justamente esa «opacidad axiológica» pueda acarrear en la práctica. El único modo en que el legislador puede determinar prácticamente de modo congruente las decisiones de la jurisdicción es, pues, atribuyendo al juez una deliberación propia en cuanto a la garantía de «verificación» in casu de esos valores a través de las reglas que está aplicando y la evitación de que se vean malogrados ${ }^{70}$. Ello está estrechamente relacionado, como es evidente, con la relación existente entre lo que FERRAJOLI llama «observancia», «actuabilidad», «aplicación sustancial» o «efectividad» de las normas (2011a: I, 159 y ss., 232 y ss., 305 y ss., 525 y ss.) y lo que antes llamábamos «producción de valor» $\mathrm{y}$ «congruencia» por las decisiones recurrentes de la jurisdicción ${ }^{71}$. Y, en relación con lo segundo, los principios y derechos constitucionales constituyen garantías exclusivamente en la medida en que expresan y protegen valores ético-políticos, pero no constituyen estos valores, lo cual significa que su faceta autoritativa se encuentra ella misma subordinada a su faceta justificativa ${ }^{72}$. Una importante consecuencia de ello es que los principios no pueden hacerse equivalentes al conjunto de reglas (es

68 «Los principios, entonces, serían normas que prescriben que se realicen ciertos valores, mientras que las reglas serían normas que modalizan deónticamente acciones determinadas descritas en términos que poseen autonomía semántica. Los principios no aclaran qué acciones en concreto materializarían o frustrarían aquellos valores; las reglas no aclaran qué valores se realizan al ejecutarse la acción que prescriben» (BAYÓN, 1996: 46).

69 «Se puede incluso afirmar que detrás de cada regla hay también un principio: hasta detrás de la prohibición de estacionamiento de los vehículos o detrás de la obligación de frenar ante el semáforo en rojo, hay principios, como los de seguridad y la mayor eficiencia y racionalidad del tráfico rodado» (2011b: 38-39).

70 ARISTÓTELES subraya que la justificación de esa capacidad correctiva reside en que el propio legislador asume la posibilidad del error: «En aquellos ámbitos en los cuales no es posible alcanzar definiciones precisas, pero es necesario razonar en términos universales, la ley tiene que remitirse a lo que se da con más frecuencia, aun a sabiendas de que puede incurrir en error» (Ét. Nic., V, 10,1137b15-18).

71 «El uso de "aplicación” en sentido sustancial resulta en efecto pertinente siempre que la observancia de una norma sustantiva se manifiesta en ese específico tipo de "coherencia" que es la "subsunción" o "correspondencia” de un determinado supuesto de hecho con la norma que lo prevé» (FERRAJOLI, 2011a: I, 532). Que la función de garantía de la jurisdicción se traduzca en la «afirmación de la ley» (2011a: II, 209) y también en su condición de «contra-poder» (id.: 291) depende en última instancia de su efectividad: «Consiguientemente, si es cierto que la independencia es un rasgo necesario de las funciones de garantía, de modo que no hay garantía de los derechos sin jueces independientes, es también cierto, a la inversa, que sólo la efectividad de tales funciones sirve para acreditar el valor de su independencia a los ojos de los ciudadanos» (2011a: II, 213).

72 Como subraya Aguiló, «una garantía independizada del valor de lo garantizado es [...] un sinsentido práctico» (2011: 60). 
decir, de obligaciones y prohibiciones) derivadas de ellos ${ }^{73}$, contra el argumento de FERRAJOLI para borrar su diferencia de estatuto consistente en asimilarlos desde el punto de vista de su violación ${ }^{74}$. La estructura normativa «abierta» de los principios -otra consecuencia del hecho de ser expresión de valores que no se refieren a cursos de acción específicos-, exige precisamente una mediación práctica deliberativa en términos de apreciaciones y reglas específicas que «cierre» determinados cursos de acción erga omnes como aquellos que mejor realizan tales valores. Esa práctica es la práctica política, tanto la legislativa como la constitucional — de los tribunales constitucionales-: ¿ ¿es la ponderación llevada a cabo por éstos necesariamente un vaciamiento de los principios y valores constitucionales o una invasión ilegítima de la esfera política de la legislación?

La respuesta tiene que ser negativa, si tenemos en cuenta que la conformación abierta de los principios impide que pueda haber a priori jerarquías completamente inmóviles o predeterminadas entre ellos in abstracto: éstas deben reconsiderarse y a veces reconfigurarse de nuevo ex post en función de las situaciones de conflicto que plantea el devenir práctica social de primer grado. En esto no hay como vimos -bajo una perspectiva pragmática - absolutamente ninguna diferencia en relación con lo que sucede con las reglas: las excepciones, lagunas y antinomias no resultan completamente previsibles por adelantado, sino que surgen y deben ser resueltas in casu. La solución no puede ser entonces insistir en convertir a toda costa los principios constitucionales en reglas que supuestamente eliminan la deliberación y la ponderación ${ }^{75}$ por carecer de conflictos (resueltos ex ante) o de excepciones (excluidas ex post), ni tampoco en considerar que la interpositio legis es la única alternativa legítima. Cabe decir más bien que los principios no pueden tener excepciones y las reglas no pueden carecer de ellas: lo que llamamos excepcionar (o violar) un principio es construir una regla resultante de una ponderación con otros principios concurrentes - algo inevitable en constituciones pluralistas que acogen valores en necesaria tensión-y lo que llamamos excepcionar una regla es acudir al principio o balance de principios que la justifica. Todas estas divergencias y anomalías implican una dialéctica que no puede ser cancelada «formalmente» por anticipado a través de medios lingüísticos: como vimos, su existencia no es un problema de determinación del lenguaje sino del contenido esencialmente valorativo de este lenguaje ligado a su dimensión práctica («de lo que es indeterminado, la regla también lo es... pero la causa de ello está en la naturaleza de la práctica»). Si la jurisdicción es la institución cuya función de garantía no sólo abarca

73 Vid. NINO, 2006: 110 y ss. El argumento de la reducción de lo axiológico a lo deontológico puede considerarse deudor de la dicotomía positivista hecho-valor.

${ }_{74}$ «[S]iempre la violación de un principio hace de él una regla que enuncia las prohibiciones o las obligaciones correspondientes (FERRAJOLI, 2011b: 40). «Y es por la posibilidad de sus violaciones, por acción o por omisión, por lo que las normas que los establecen [los derechos fundamentales] son caracterizables como reglas deónticas» (FERRAJOLI, 2012: 803; cfr. 804). Cfr. 2011a: I, 553-555. La misma posición se mantiene en FERRAJOLI (2013: $\$ 2$ : «frente a su violación el principio que enuncia un derecho fundamental se transforma en una regla»). Naturalmente, la determinación del perímetro de acciones y omisiones que justificadamente aparecen como «violaciones» de las respectivas prohibiciones y obligaciones no resulta posible solamente a base de relaciones lógicas o lingüísticas: exige consideraciones acerca del carácter valioso o disvalioso de las mismas. También la denotación de los derechos fundamentales depende de su connotación valorativa.

75 «Lo que sí resulta bien llamativo y extraño es que un no-cognoscitivista sea partidario de una constitución sustantiva, rígida y cerrada a la deliberación; es decir, partidario de un "deber ser" no derogable y no moldeable en su aplicación» (AGUILÓ, 2011: 66). 
a las reglas sino también, como hemos visto, a los valores o razones político-morales a que ellas sirven entonces el único modo por el que puede «determinar» los principios constitucionales en que se proclaman esos valores y razones es la ponderación de los mismos mediante la construcción, cuando concurren en un caso, de nuevas reglas que establezcan pro futuro las condiciones de precedencia entre ellos, válidas y generalizables para casos similares ${ }^{76}$, de un modo estructuralmente simétrico a lo que sucede con la «ponderación legislativa» que FERRAJOLI considera en general «fisiológica» (2011: 44-46). Los inevitables conflictos entre ambos —entre el tribunal constitucional (como tribunal político o «legislador negativo») y el legislador democrático-a la hora de interpretar los valores y derechos constitucionales no pueden ser resueltos recurriendo a otro método: en particular, no pueden serlo mediante el expediente de «blindar» los principios-reglas de la constitución y estipular que esos conflictos constituyen «violaciones» («antinomias y lagunas estructurales»). Pues ello implica la evidente circularidad de que determinar lo que constituya «violación» de esos principios constitucionales que figuran como puras «formas» inderogables es dependiente a su vez de ponderaciones (ni siquiera las reglas operan «todo-o-nada»), tanto en relación con el diseño de las leyes que colman las lagunas como en relación con la anulación de las antinomias, que sólo puede ser judicial (la jurisdicción es precisamente definida como «la comprobación de violaciones por causa de actos ilícitos o inválidos»: FERRAJOLI, 2011a: II, 209). Solamente son razones sustantivas (es decir, el resultado de una ponderación entre principios institucionales y sustantivos) aquellas que pueden llevar a someter a la práctica judicial a un régimen de autorrestricción o deferencia formal al legislador (del juez constitucional) o a la administración (del juez ordinario), del mismo modo que ello sucede, como vimos, cuando la propia legislación ordinaria pretende sujetar a los jueces a un régimen estricto de reglas (p. ej., en el derecho penal). Lo que ninguno de ambos regímenes podría significar es que se privase a los jueces de una deliberación valorativamente fundada, reduciendo su función a un desempeño axiológicamente pasivo e inerte, meramente «cognoscitivo». Ello sería reproducir y aumentar respecto de la constitución el mismo error que el legalismo ilustrado cometió respecto de la legislación al pretender prohibir su interpretación. Y ni siquiera ideológicamente parece tener mucho sentido hoy presentar como «cognición» o deducción analíticamente verdadera a partir del material jurídico-constitucional tomado como lenguaje denotativo lo que necesariamente es el resultado de juicios de valor connotativos de contenido político-moral cuya corrección y justificabilidad argumentadas son exigibles en todo caso como parte esencial de la función judicial en una democracia. La clase de equidad que demanda el Estado de derecho constitucional no podría ser, por ello, la ferrajoliana sino más bien la aristotélica.

\section{REFERENCIAS}

Aguiló, J., 2011: «El constitucionalismo imposible de Luigi Ferrajoli», Doxa, 34: 55-71.

AmayA, A., 2012: «La coherencia en el derecho», Doxa, 35: 59-90.

Aristóteles, The Complete Works of Aristotle: The Revised Oxford Translation [1984], ed. de J. BARnES, Princeton: Princeton University Press 1995. Ética a Nicómaco, trad. de ARAU-

76 Ruiz Manero, 2012. 
jo-Marías, CEPC: 2009 (9. ${ }^{a}$ ed.); Política, trad. de Araujo-Marías, CEPC: 2005 (6. a ed.); Retórica, trad. de A. TOVAR, Madrid: CEC, 1990 (4. . ed.).

ATIENZA, M., 2005: «El derecho como argumentación», en M. ATIENZA y L. FERRAJOLI, Jurisdicción y argumentación en el Estado constitucional de derecho, México: UNAM, 1-86.

- 2013: Curso de argumentación jurídica, Madrid: Trotta.

AtRIA, F., 1999: «Del derecho y del razonamiento jurídico», Doxa, 22: 79-119.

BAYÓN, J. C., 1996: «Principios y reglas: legislación y jurisdicción en el Estado constitucional», Jueces para la democracia, 27: 41-49.

BeCCARIA, C., 1968: De los delitos y de las penas (1774), trad. de J. A. DE LAS CASAS, Madrid: Alianza.

BodÉÜs, R., 1993: The Political Dimensions of Aristotle's Ethics (1982), trad. J. E. GARRETT, Albany: SUNY Press.

Dworkin, R., 1986: Law's Empire, Harvard: Belknap Press.

— 2010: «¿Deben nuestros jueces ser filósofos? ¿Pueden ser filósofos?», Isonomía, 32: 7-29 (trad. L. GARCÍA JARAMILlO).

- 2011: Justice for Hedgehogs, Cambridge: Harvard University Press.

FERRAJOLI, L., 2000: Derecho y razón. Teoría del garantismo penal (1989), trad. de P. AndRÉs et al., Madrid: Trotta.

- 2004: Epistemología jurídica y garantismo, México: Fontamara.

- 2005: «El papel de la función judicial en el Estado de derecho», en M. ATIENZA y L. FerRAJOLI, Jurisdicción y argumentación en el Estado constitucional de derecho, cit., 87-108.

- 2011a: Principia iuris. Teoría del derecho y de la democracia (2007), vols. I y II, trad. de J. C. Bayón, M. Gascón, L. Prieto, A. Ruiz Miguel y P. Andrés, Madrid: Trotta.

- 2011b: «Constitucionalismo principialista y constitucionalismo garantista», Doxa, 34: 15-53.

- 2011-12: «Doce cuestiones en torno a Principia iuris», Eunomía. Revista en Cultura de la Legalidad, 1: 3-34.

— 2012: «El constitucionalismo entre principios y reglas», Doxa, 35: 791-817.

- 2013: «Dos concepciones de los principios. Una respuesta a Juan Ruiz Manero», Doxa, 36.

HarT, H. L. A., 1958: «Positivism and the Separation of Law and Morals», Harvard Law Review, 71: 593-529.

- 1994: The Concept of Law (1961), Oxford: Clarendon Press, 2. ${ }^{\text {a }}$ ed. a cargo de P. A. Bulloch y J. RAZ.

LAPORTA, F. J., 2009: El imperio de la ley. Una visión actual, Madrid: Trotta.

LIFANTE VIDAL, I., 1999: «Interpretación y modelos de derecho. Sobre el papel de la intención en la interpretación jurídica», Doxa, 22: 171-193.

- 2013: «El derecho como práctica interpretativa», Ponencia presentada a las Jornadas sobre el legado de Dworkin a la filosofía del derecho, Madrid: CEPC, 29-30 de octubre de 2013.

MacCormick, N., y Summers, R. S. (eds.), 1991: Interpreting Statutes. A Comparative Study, Aldershot: Dartmouth.

Marmor, A., 2001: Positive Law and Objective Values, Oxford: Clarendon Press.

- 2005: Interpretation and Legal Theory (1992), Oxford: Hart Publishing (2. ${ }^{a}$ ed.).

Miller, F. D., 1995: Nature, Justice, and Rights in Aristotle's Politics, Oxford: Clarendon Press.

NinO, C. S., 1994, Derecho, moral y política, Barcelona: Ariel.

- 2006: La validez del derecho (1985), Buenos Aires: Astrea.

RAZ, J., 1996: «Intention in Interpretation», en R. P. GEORGE (ed.), The Autonomy of Law. Essays on Legal Positivism, Oxford: OUP, 249-286.

RocA, V., 2005: Derecho y razonamiento práctico en Carlos S. Nino, Madrid: CEPC. 
RóDENAS, A., 2012: Los intersticios del derecho. Indeterminación, validez y positivismo jurídico, Madrid: Marcial Pons.

Ruiz Manero, J., 2012: «A propósito de un último texto de Luigi Ferrajoli. Una nota sobre reglas, principios, "soluciones en abstracto" y "ponderaciones equitativas"», Doxa, 35: 819832.

SCHAuer, F., 2002: Playing by the Rules. A Philosophical Examination of Rule-Based DecisionMaking in Law and in Life [1991], New York: Oxford UP.

SHINER, R. A., 1994: «Aristotle's Theory of Equity», Loyola of Los Angeles Law Review, 27/4: $1245-1264$.

TARuffo, M., 2002: La prueba de los hechos [1992], trad. de J. Ferrer, Madrid: Trotta.

TomÁs DE AQuino: In decem libros Etbicorum Aristotelis ad Nicomachum expositio, ed. R. M. SPIAZZI. Taurini: Marietti, 1964 (3. ${ }^{a}$ ed.), trad. de A. MALlEA, Comentario a la Ética a Nicómaco de Aristóteles, Pamplona: EUNSA, 2010.

VegA, J., 2010: «Aristotle's Concept of Law: Beyond Positivism and Natural Law», Journal of Ancient Philosopby, IV/2: 1-31.

— 2013a: «Legal Rules and Epieikeia in Aristotle. Post-positivism Rediscovered», en L. HuPPes-Cluysenaer y N. M. M. S. Coelho (eds.), Aristotle and The Philosophy of Law: Theory, Practice and Justice, Dordrecht: Springer, 171-201.

- 2013b: «Aristotle on Practical Rules, Universality, and the Law», en F. J. ConTRERAS (ed.), The Threads of Natural Law: Unravelling a Philosophical Tradition, Dordrecht: Springer, $1-25$.

WEBER, M., 1973: «Die «Objektivität» sozialwissenschaftlicher und sozialpolitischer Erkenntnis» [1904], y «Der Sinn der "Wertfreiheit" der soziologischen und ökonomischen Wissenschaften» [1917], en Gesammelte Aufsätze zur Wissenschaftslebre, ed. J. WinCKELMANN, Tübingen: Mohr (4. a ed.), 146-214 y 489-540.

Wittgenstein, L., 1999: Philosophical Investigations [1953, 1982], trad. G. E. M. Anscombe, Oxford: Blackwell.

Zahnd, E. G., 1996: «The Application of Universal Laws to Particular Cases: A Defense of Equity in Aristotelianism and Anglo-American Law», Law and Contemporary Problems, 59/1: 263-295. 